\title{
Morphology, Thermal Stability, and Flammability Properties of Polymer-Layered Double Hydroxide (LDH) Nanocomposites: A Review
}

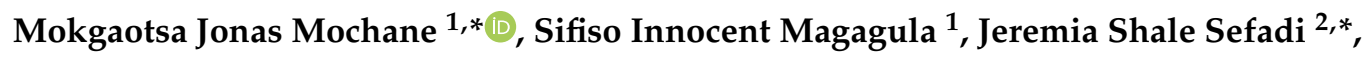 \\ Emmanuel Rotimi Sadiku ${ }^{3}(1)$ and Teboho Clement Mokhena ${ }^{3}($ ) \\ 1 Department of Life Sciences, Central University of Technology, Free State, Private Bag X20539, \\ Bloemfontein 9300, South Africa; smagagula@cut.ac.za \\ 2 Department of Physical and Earth Sciences (PES), Sol Plaatje University, Kimberley 8301, South Africa \\ 3 Department of Chemical, Institute of NanoEngineering Research (INER), \\ Metallurgical and Materials Engineering, Tshwane University of Technology, RSA, Pretoria 0001, \\ South Africa; SadikuR@tut.ac.za (E.R.S.); mokhenateboho@gmail.com (T.C.M.) \\ * Correspondence: mochane.jonas@gmail.com or mmochane@cut.ac.za (M.J.M.); jeremia.sefadi@spu.ac.za (J.S.S.) \\ Received: 15 May 2020; Accepted: 1 July 2020; Published: 14 July 2020

\begin{abstract}
The utilization of layered nanofillers in polymer matrix, as reinforcement, has attracted great interest in the 21st century. This can be attributed to the high aspect ratios of the nanofillers and the attendant substantial improvement in different properties (i.e., increased flammability resistance, improved modulus and impact strength, as well as improved barrier properties) of the resultant nanocomposite when compared to the neat polymer matrix. Amongst the well-known layered nanofillers, layered inorganic materials, in the form of LDHs, have been given the most attention. LDH nanofillers have been employed in different polymers due to their flexibility in chemical composition as well as an adjustable charge density, which permits numerous interactions with the host polymer matrices. One of the most important features of LDHs is their ability to act as flame-retardant materials because of their endothermic decomposition. This review paper gives detailed information on the: preparation methods, morphology, flammability, and barrier properties as well as thermal stability of $\mathrm{LDH} /$ polymer nanocomposites.
\end{abstract}

Keywords: nanocomposites; nanofillers; thermal stability; flammability; polymer matrix

\section{Introduction}

Polymer matrices are normally reinforced with inorganic fillers in order to improve their properties and widen their applications [1]. The well-known fillers include silicate, carbon based, calcium carbonate, fibres, etc. It is apparent that the incorporation of filler requires high content in order to have any significant influence of the properties of the polymer matrices. A higher composition of fillers, in most cases, results in increased weight of the resultant composites, which limits the applications of such systems. In order to solve the problem of weight, nanoparticles have recently emerged as the filler of choice to enhance the properties of the resultant polymer matrix. This is due to the ability of nanoparticles to influence the properties of a polymer matrix with considerably low contents, thereby allowing the nanocomposites to maintain low density of the polymer matrix.

The incorporation of layered inorganic fillers into polymer matrices to form polymer/layered inorganic nanocomposites has attracted a lot attention due to their distinctive properties [2]. Layered double hydroxides/polymer nanocomposites belong to an important class of polymer/layered inorganic nanocomposites because they have shown significant improvement in the composites' thermal stability, flame retardancy, and improvement in overall physical properties [3,4]. Due to high pressure that 
can limit or prohibit the use of halogen flame retardant materials because of environmental concerns, LDHs have emerged as a suitable candidate for halogen-free flame-retardant material [5-8]. It is well documented in the literature that the methods used for the synthesis of LDH include: urea hydrolysis, hydrothermal synthesis, co-precipitation, and ion exchange $[9,10]$.

From a chemistry point of view, the structure of LDH can be presented by the following formula: $\left[\mathrm{M}^{\mathrm{II}}{ }_{1-\mathrm{x}} \mathrm{M}_{\mathrm{x}}^{\mathrm{III}}(\mathrm{OH})_{2}\right]_{\text {intra }}\left[\mathrm{A}_{\mathrm{x} / \mathrm{m}}{ }^{\mathrm{m}-} \cdot \mathrm{nH}_{2} \mathrm{O}\right]_{\text {inter }}$.

In the formula, inter and intra are the intralayer crystalline domain and interlayer spaces, respectively. The layers of the LDHs are positively charged edge-shared octahedral coordinated metal hydroxide crystal structures, sandwiched by charge compensating interlayer anions with optional solvation in water. Furthermore, $\mathrm{M}^{\mathrm{II}}\left(\mathrm{M}^{2+}\right)$ is the divalent cation, whereas $\mathrm{M}^{\mathrm{III}}\left(\mathrm{M}^{3+}\right)$ is the trivalent cation and $\mathrm{A}$ is described as an anion with the valency $\mathrm{m}$. Nevertheless, it is apparent that LDHs consist of high charge density in the interlayer and they seem to have an impenetrable action between the hydroxides when compared with the well-known layered silicates, which makes exfoliation very difficult [2]. Furthermore, the fact that polymers are hydrophobic results in further hindrance of the polymer chains into the LDHs. It is very clear that there is the need to incorporate anionic materials in order to improve the intercalation of polymers into the LDHs layers. The easiest and convenient route for fabrication of polymer/LDHs with improved properties is to modify the clay with surfactant or other materials with the aim of preparing a stable LDHs/polymer nanocomposite system. This review paper discusses the different modifications of LHDs and the preparation of polymer nanocomposites with enhanced properties, i.e., better dispersion, flammability resistance, and thermal stability.

\section{History of Layered Double Hydroxides (LDHs)}

The existence of LDHs dates back to 1842, where minerals consisting of LDHs were discovered in Sweden. The laboratory synthesis of LDHs began in 1942 and was based on the reaction of dilute metal solutions with bases. Due to their structural similarities to the hydrotalcites, LDHs were referred to as hydrotalcite-like compounds (HTLCs). Hydrotalcites are compounds that exist as hydroxycarbonates of magnesium and aluminium or magnesium and iron (pyroaurite). These hydroxycarbonates are found in nature, in the form of foliated and twisted plates [11]. In the early 1970s, hydrotalcites began to be used as catalysts and precursors of various catalysts. This triggered a lot of interest towards the research of LDHs [11,12]. The first studies on the single crystal X-ray diffraction of minerals revealed that LDHs possessed a layered structure. Each layer consists of two cations and the interlayer space was filled with water and carbonate ions. However, at first, this was debated by several researchers. The reason for this was that even though the main components of the LDH structure had been identified, some researchers still felt that the intrinsic details associated with the structural components of LDHs were not yet understood [13]. LDHs can be formed naturally through natural processes and synthetically in the laboratory. In nature, LDHs are formed naturally by natural processes, such as the weathering of basalt rocks $[14,15]$ and the precipitation [16] of saline water. As mentioned earlier, the structure of LDHs resembles that of naturally occurring hydrotalcites with the formula, $\left[\mathrm{Mg}_{6} \mathrm{Al}_{2}(\mathrm{OH})_{16}\right] \mathrm{CO}_{3} \cdot 4 \mathrm{H}_{2} \mathrm{O}$ and a general formula, $\left[\mathrm{M}(\mathrm{II})_{1-\mathrm{x}} \mathrm{M}(\mathrm{III})_{\mathrm{x}}(\mathrm{OH})_{2}\right]\left(\mathrm{Y}^{\mathrm{n}-}\right)_{\mathrm{x} / \mathrm{n}} \cdot \mathrm{YH}_{2} \mathrm{O}$, where $\mathrm{M}(\mathrm{II})$ and $\mathrm{M}(\mathrm{III})$ are divalent and trivalent metals, respectively; $0.2<\mathrm{x}<0.33$ and $\mathrm{Y}^{\mathrm{n}-}$ are exchangeable interlayer anions [17-19]. Synthetically formed LDHs have a highly hydrophilic nature with an amorphous or semicrystalline hexagonal structure. The structure of the LDH layers is based on the brucite compound $\left[\mathrm{Mg}(\mathrm{OH})_{2}\right]$. The layers that are adjacent to each other are usually tightly bound together [11]. The structure of LDHs is shown in Figure 1. 


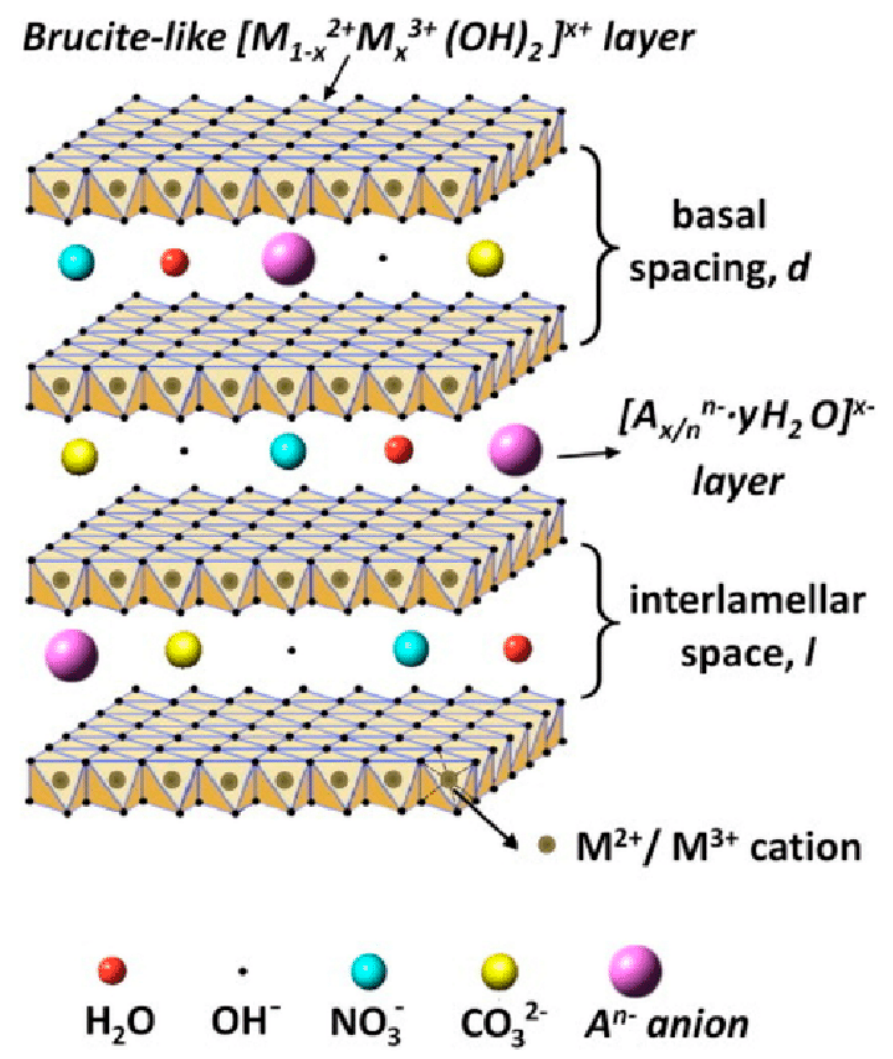

Figure 1. General chemical structure of layered double hydroxides (LDHs) [10].

During the synthesis of LDHs, many different combinations of divalent and trivalent metal cations are used; these include: magnesium, aluminium, zinc, nickel, chromium, iron, copper, indium, gallium, and calcium $[17,20-22]$.

LDHs are usually preferred over clays or other layered materials. This is because the synthesis of LDHs has the potential of forming LDHs with a wide range of compositions and metal-ion combinations. Their preference over clay is also due to the fact that LDHs have high charge density. The charge density of the LDHs is determined by the ratio of the divalent and trivalent metal cations. If the divalent/trivalent ratio is low, the charge density increases [11]. LDHs have unique physical and chemical properties that are closely related to those of clays. The positively charged layered structure of LDHs induces properties, such as anion mobility, surface basicity, and anion exchangeability. The water and the anions found between the layers of LDHs are labile. Therefore, exchange reactions can be used to replace these interlayer anions with various inorganic or organic anions [23]. When LDHs are calcinated, mixed metal oxides with properties, such as large surface area and surface basicity are obtained. At elevated temperatures, the metal oxides formed also form a homogenous mixture with small crystallite sizes [11]. The LDHs and metal oxides formed during calcination also have a high catalytic activity.

LDHs possess a structural reconstruction or memory effect property that is only unique to them. Structural reconstruction is a property that is induced by the calcination of LDHs and the treatment of metal oxides with a specific anionic solution [24]. These materials can easily adsorb anions and cations $[25,26]$. The magnetic properties of LDHs are usually regulated by the chemical nature of the interlayer spaces in them. The chemical environment in these spaces can be modified by the intercalation with organic anions of different chain lengths. This results in hybrid materials with tunable magnetic properties [27]. The intercalation of LDHs with long-chain surfactants, e.g., dodecyl sulphates, forms hybrid materials that swell in organic solvents. This swelling characteristic is usually exploited in the fabrication of monolayers used in nanohybrid and nanocomposite synthesis [28]. 
The chemical environment in between the layers of LDHs is usually altered by the exchange of anions. The exchange of anions follows the following order of preference:

$$
\mathrm{NO}_{3}^{-}<\mathrm{Br}^{-}<\mathrm{Cl}^{-}<\mathrm{F}^{-}<\mathrm{OH}^{-}<\mathrm{SO}_{4}{ }^{2-}<\mathrm{CO}_{3}^{2-}
$$

Here, the $\mathrm{NO}_{3}^{-}$anion can be easily replaced by the $\mathrm{CO}_{3}^{2-}$ anion. Therefore, in the preparation of a precursor for interaction, the $\mathrm{NO}_{3}^{-}$anion is preferred over the $\mathrm{CO}_{3}^{2-}$ anion. This is because the interaction has to happen in such a manner that the introduction of the guest molecule does not change the structure of the host. During this interaction, the existing ion is replaced by the guest molecule. The anions that are weakly bonded to the hydroxide layers are usually the most vulnerable for replacement by other ions [29-31].

Many different methods are used for the synthesis of LDHs. The type of method used depends on the required characteristics and applications of the resultant material. The most commonly used methods/techniques are methods such asco-precipitation, hydrothermal synthesis, urea hydrolysis, sol-gel, ion-exchange, and rehydration. There also are other methods often employed, such as self-oxide method, template synthesis method, and surface synthesis method. The co-precipitation method is one of the commonly used methods. In this method, the LDH structure is formed by the mixing of aqueous solutions of $\mathrm{M}(\mathrm{II}), \mathrm{M}(\mathrm{III})$, and interlayer anions. This method gives the liberty to prepare LDHs that consist of a wide range of anions and cations. The co-precipitation method is uniquely used to prepare organic-anion LDHs [13]. The co-precipitation method can be further subdivided into three other methods, viz co-precipitation by filtration, co-precipitation at lower supersaturation, and co-precipitation at higher supersaturation methods.

The hydrothermal synthetic method is usually employed to regulate particle size and particle size distribution. The hydrothermal synthesis method follows two synthesis routes. The first route is where the materials are prepared at temperatures above $373 \mathrm{~K}$ in a pressured autoclave. Here, the LDHs are synthesized from $\mathrm{MgO}$ and $\mathrm{Al}_{2} \mathrm{O}_{3}$ precursors or from mixtures formed through the decomposition of the precursor nitrate compounds $[11,32,33]$. In the other synthesis route, LDHs are prepared at low temperatures and are also subjected to a process of aging. During the aging process, the LDH precipitate is refluxed at a specific temperature for $18 \mathrm{~h}$.

In the urea hydrolysis method, urea is used as a precipitation agent in the synthesis of LDHs, at specific temperatures. The degree of crystallinity of LDHs depends on the synthesis temperature and decomposition rate. At low temperatures, large particles are formed due to the slow nucleation and slow decomposition rates of the urea [34,35]. The urea hydrolysis method is uniquely used in the synthesis of LDHs with a high charge density [34].

In the sol-gel method, LDHs are produced by first forming a sol via the hydrolysis and partial condensation of a metallic precursor, followed by the formation of a gel. Here, the hydrolysis and condensation rates of the metallic precursors determine the properties of the resultant LDHs [36]. The condensation and hydrolysis rates of the metallic precursors are also susceptible to modification by various reaction parameters, such as $\mathrm{pH}$, type and concentration of the precursor, synthesis temperature, and solvent used. The sol-gel method forms LDHs with a larger surface area than those formed by the co-precipitation method [37-39]. However, properties such as basicity as well as the divalent and trivalent metal ion molar ratios of LDHs synthesized with the sol-gel method are still not understood [38-40].

The ion-exchange method involves the exchange of interlayer anions with other guest anions introduced into the LDH structure in order to obtain the LDH-guest compound. Several factors, such as affinity towards the guest anions, the medium of exchange, $\mathrm{pH}$, and the chemical nature of the brucite layers affect the ion-exchange in LDHs [41].

In the rehydration method, the mixed metal oxides formed after the calcination of LDHs at high temperatures between $500-800{ }^{\circ} \mathrm{C}$ are rehydrated and formed into an LDH structure in the presence of the desired anions [42-47]. 


\section{Selective Polymer Matrices for Fabrication LDHs}

Polymer matrices are frequently reinforced by different nanofillers to reduce the limitations of polymers and widen their applications. LDHs nanofillers have been incorporated into polymer matrices to improve the mechanical properties, flammability resistance, and the overall physical properties of polymers. Polymer matrices in nanofiller polymer nanocomposites are used to provide shape and durability in the nanocomposites.

Different polymer matrices have been used for fabrication of polymer-LDHs nanocomposites. The polymer matrices include polymethyl methacrylate (PMMA), epoxy, polylactic acid (PLA), polyvinyl chloride (PVC), polypropylene (PP), poly(ethylene terephthalate)(PET), polystyrene (PS), polyaniline, low-density polyethylene (LDPE), acrylonitrile-butadiene-styrene (ABS), ethylene vinyl acetate (EVA), linear low density polyethylene (LLDPE), cellulose, and poly(caprolactone) [48-60]. Based on the polymer matrices mentioned above, it is clear that thermoplastic and thermosets were used as host matrices for preparation of LDHs-nanocomposites. However, it is apparent that thermoplastic matrices were preferred over the thermosets because the former are lightweight, can be re-melted, and shaped. Due to an environmental protection, there is a slight shift towards fabrication of biopolymer matrix/LDHs nanocomposites. The resultant nanocomposite is termed "green nanocomposite", and these nanocomposites are favourites to replace petroleum-based plastics. Table 1 summarizes selective polymer matrices for preparation of LDHs nanocomposites.

Table 1. LDHs nanocomposites with selective polymer matrices.

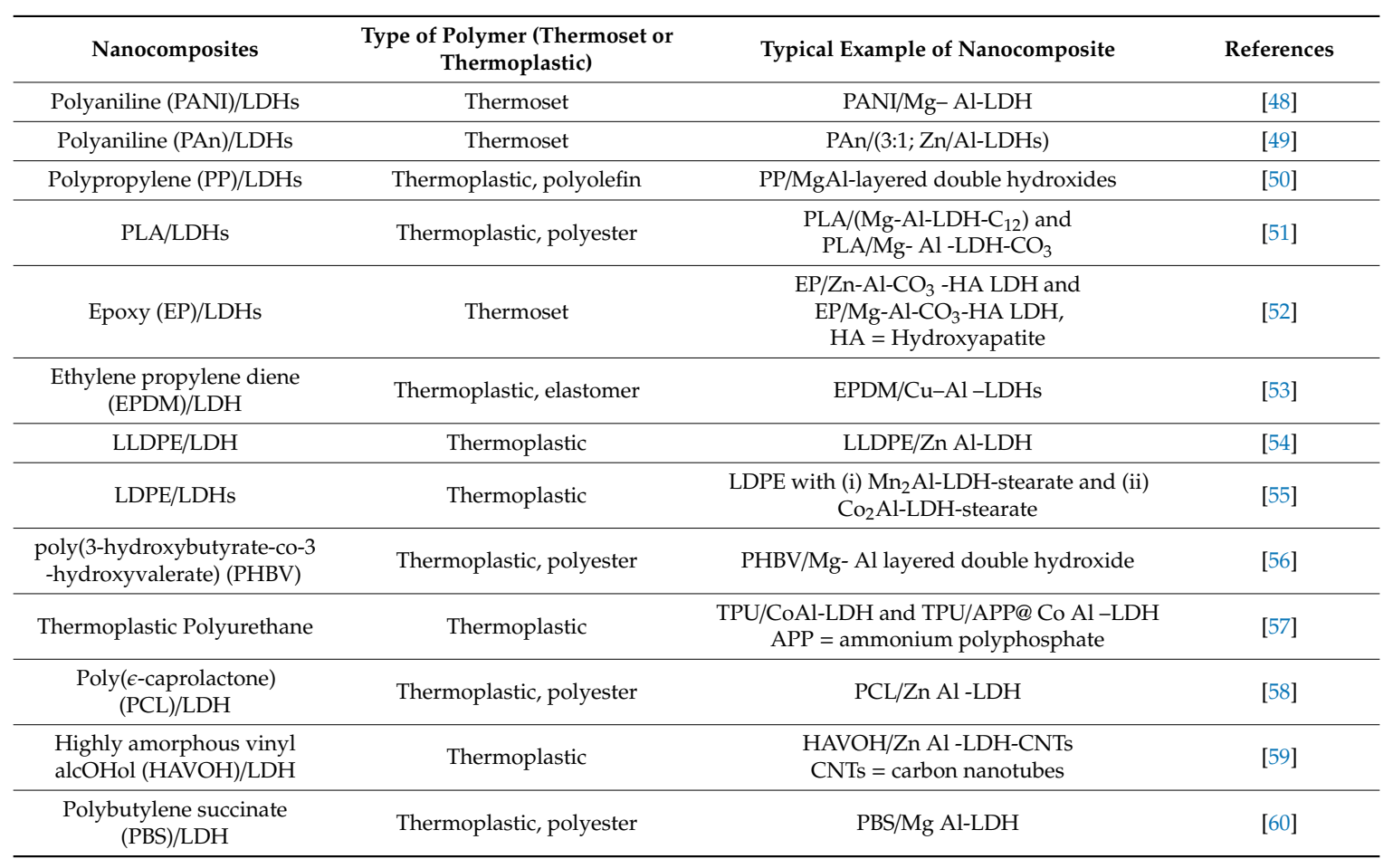

\section{Preparation and Morphology of Polymer-LDHs Nanocomposites}

In most studies, it was explained that dispersion of the filler/nanofiller within a polymer matrix plays a very important role in the properties of the fabricated polymer nanocomposite. In an LDHs/polymer system, the LDHs are normally modified with organic anions in order to enhance their interactions with polymer matrices. The main reason for improving the interaction between the two components, i.e., polymer and LDHs, is because the polymer is hydrophobic and LDHs is hydrophilic [61]. Furthermore, the method of preparation was also found to have a huge impact on the dispersion of the LDHs within the polymer matrix. The literature has shown that in most cases, LDHs are fabricated with different metals, depending on the desired applications. Leng and co-workers 
investigated the structure-property relationship of composites formed from polylactic acid (PLA) and layered double hydroxides and the comparison of MgAl and NiAl LDH as nanofillers [62]. The metal (s) LDHs were organically modified with sodium dodecyl benzene sulfonate (SDBS). LDHs and PLA were prepared by a melt mixing process at a temperature of $190{ }^{\circ} \mathrm{C}(463 \mathrm{~K})$. The morphological comparison was based on a $3 \mathrm{wt}$ \% content of LDH. Large particles with an estimated size of $100 \mathrm{~nm}$ with less agglomerates were obtained for MgAl LDH/PLA (Figure 2A). According to the authors, this arrangement will allow partial exfoliation of the metal $\mathrm{Al} / \mathrm{LDH}$ layers. However, in the system fabricated from NiAl/LDH-PLA, more aggregates were reported. The structures obtained are more favourable to intercalation than exfoliation. With the findings obtained above, it can be summarized that the system of $\mathrm{NiAl} / \mathrm{LDH}-\mathrm{PLA}$ favoured intercalation, whereas the MgAl/LDH-PLA nanocomposites is a typical exfoliated system.

\section{MgAl/LDH-PLA}
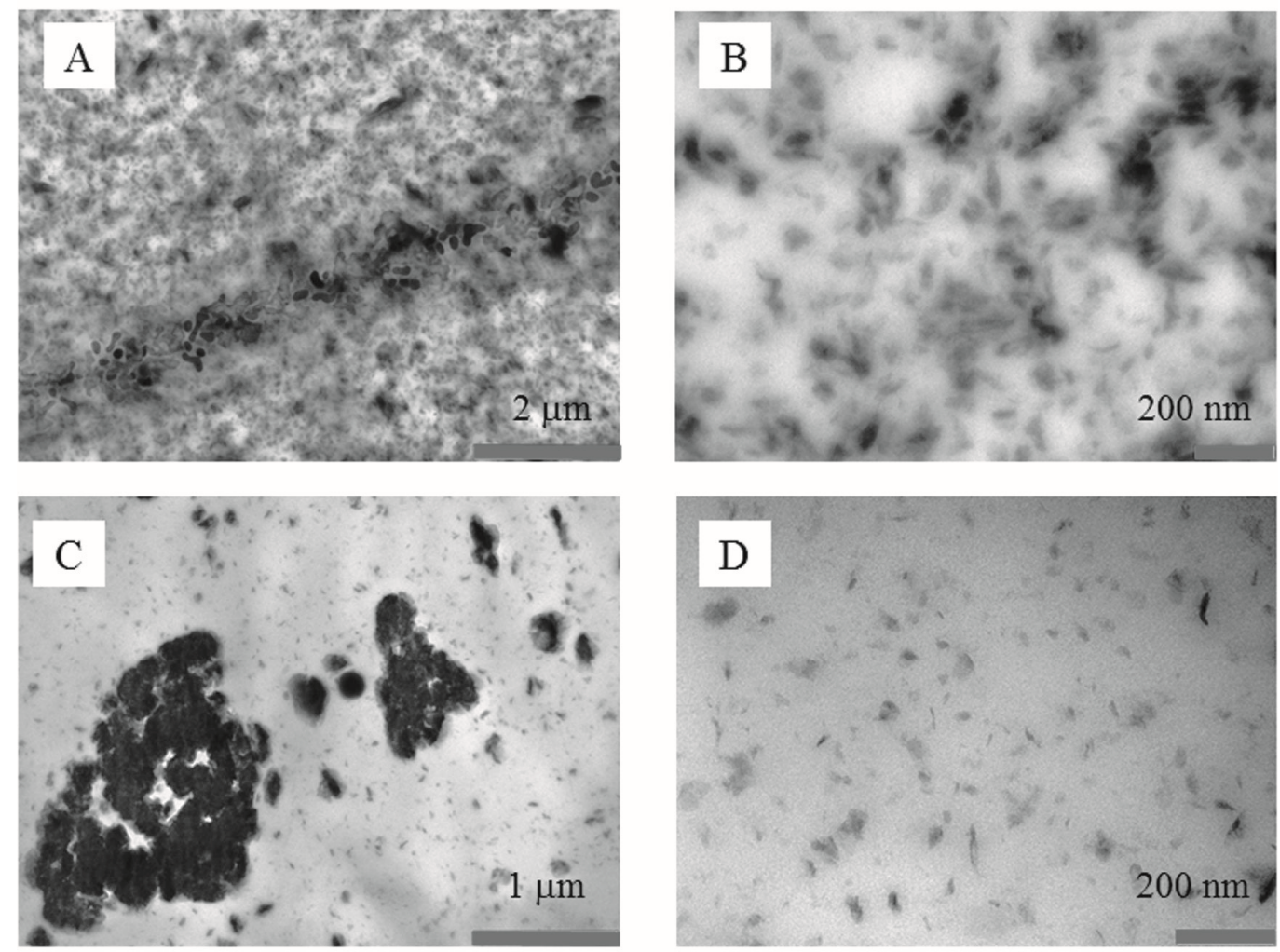

\section{NiAIAI/LDH-PLA}

Figure 2. TEM picture for nanocomposites with an $\mathrm{LDH}$ concentration of $3 \mathrm{wt}$.\%. (A) MgAl/LDH-PLA size bare $2 \mu \mathrm{m}$; (B) MgAl/LDH-PLA size bare $200 \mathrm{~nm}$; (C) NiAl/LDH-PLA size bare $1 \mu \mathrm{m}$; (D) $\mathrm{NiAl} / \mathrm{LDH}-\mathrm{PLA}$ size bare $200 \mathrm{~nm}$ [62].

Quispe-Dominguez et al. [63] investigated two types of mixing methods in order to compare which method provides better dispersion of MgAl-DBS LDH in a PLA matrix. LDH was modified with sodium dodecylbenzene sulfonate (DBS). The methods employed in this study include: (i) sonication-assisted masterbatch melt mixing and (ii) direct melt mixing. Sonication-assisted masterbatch melt mixing was undertaken by dissolving PLA and MgAl-DBS in methylene chloride as a solvent. After $12 \mathrm{~h}$ and at a temperature of $80^{\circ} \mathrm{C}$, the solvent was evaporated, with the masterbatch formed, processed at $170{ }^{\circ} \mathrm{C}$ in a twin-screw compounder for $10 \mathrm{~min}$. However, for direct mixing, there was no need for solvent mixing; PLA and MgAl-DBS were melt-mixed directly at $170{ }^{\circ} \mathrm{C}$ for $10 \mathrm{~min}$. It was observed that the sonication-assisted masterbatch melt mixing method resulted in better dispersion, intercalation, and exfoliation of LDH when compared to direct mixing for all investigated compositions. The particle 
size of the metal (s)-LDHs nanofiller has been proven to have an influence on the dispersion of the nanofiller within a polymer matrix [64]. It was reported that the fabrication of LDH with gel resulted in large particle sizes (of between 3-4 $\mu \mathrm{m}$ ), whereas the preparation of LDH nanoparticles through sonication produced smaller nanoparticles (of between 50-200 nm) (Figure 3). The nanocomposites with compositions of between 1-10 wt.\% of $\mathrm{Mg}-\mathrm{Al} \mathrm{LDH}$ were prepared by the modified solution mixing method. The authors reported better dispersion for smaller sonicated LDH nanoparticles within isotactic polypropylene (iPP) matrix, as confirmed by wide angle $\mathrm{x}$-ray diffraction (WAXD) and atomic force microscopy. Table 2 illustrates the summary of some selective studies on the preparation and morphology of polymer-LDHs nanocomposites.

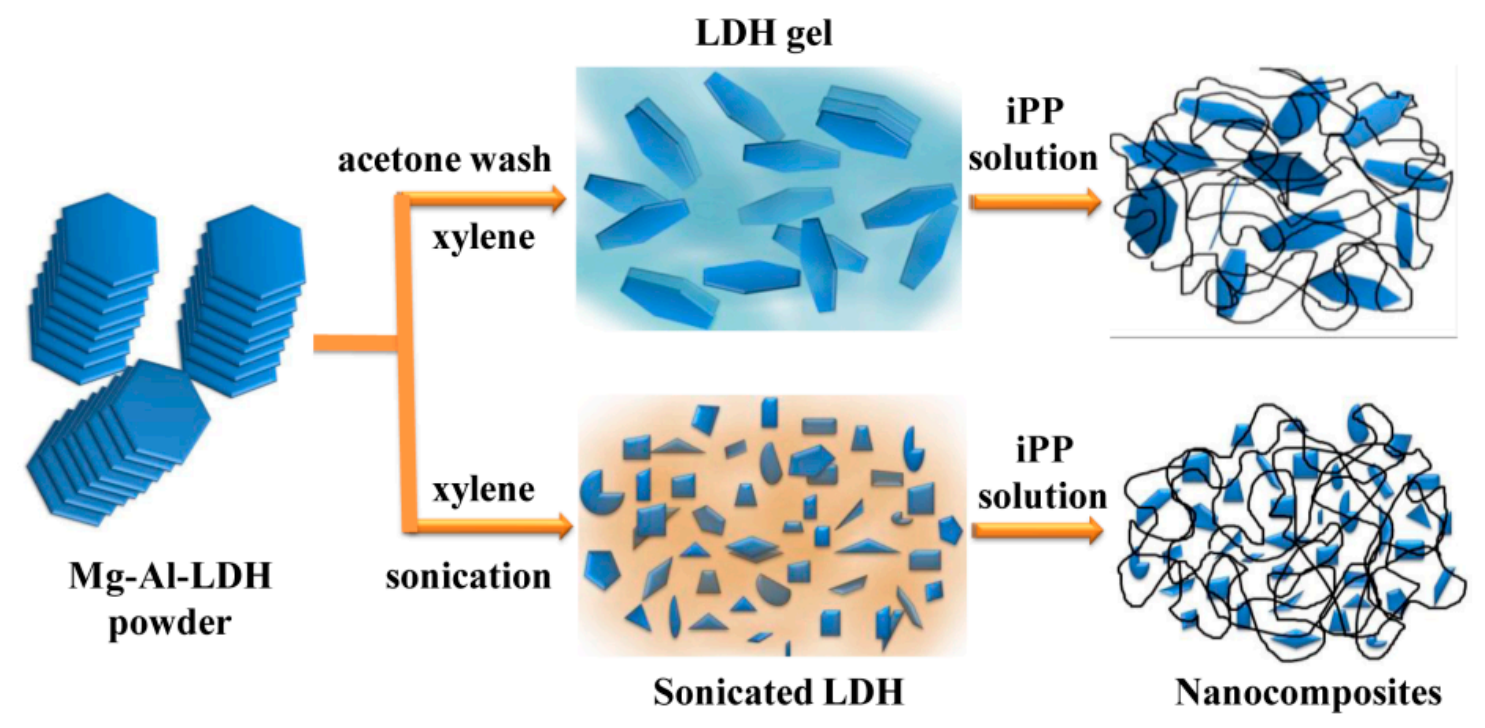

Figure 3. Graphic representation of the preparation of isotactic polypropylene/Mg-Al LDH layered double hydroxide nanocomposites [64]. 
Table 2. Selective studies on preparation and morphology of polymer-LDHs nanocomposites.

\begin{tabular}{|c|c|c|c|c|}
\hline Polymer/LDHs System & Synthesis of the Metal-LDH Nanofiller & $\begin{array}{l}\text { Preparation Method of the } \\
\text { Nanocomposites }\end{array}$ & Summary of the Resultant Morphology & References \\
\hline Polyurethane $(\mathrm{Pu}) / \mathrm{CoAl}-\mathrm{LDH}$ & Urea hydrolysis & In-situ intercalation polymerization & The exfoliation of the nanofiller within a matrix was reported. & [65] \\
\hline $\begin{array}{l}\text { Functionalized Poly (vinyl } \\
\text { chloride) (PVC)/Mg-Al LDH }\end{array}$ & Co-precipitation method & Solution intercalation method & $\begin{array}{l}\text { Four different nanocomposites were prepared depending on the chemical } \\
\text { functionalizing of PVC: (i) PVC/Mg-Al LDH (ii) (PVC+thiosulfate)/Mg-Al } \\
\text { LDH (iii) (PVC+sulfate)/Mg-Al LDH (iv) (PVC+thiourea)/Mg-Al LDH. } \\
\text { Amongst all formed nanocomposites, more exfoliated structures were } \\
\text { observed for (PVC+thiourea)/Mg-Al. }\end{array}$ & {$[66]$} \\
\hline $\begin{array}{l}\text { Polyacrylonitrile (PAN)/Zn-Al } \\
\text { LDH }\end{array}$ & Co-precipitation & In-situ polymerisation technique & $\begin{array}{l}\text { Different LDH content (viz 2, 4, 6, 8\%) were synthesized with PAN. } \\
\text { Transmission electron microscopy (TEM) showed disordered dispersion of } \\
\text { nanofiller in the PAN matrix. However, at higher content of the nanofiller } \\
\text { (viz 8\%), more agglomerates were obtained. }\end{array}$ & [67] \\
\hline $\begin{array}{c}\text { Poly(methyl } \\
\text { methacrylate)/Mg-Al LDH } \\
\text { (PMMA/LDH) }\end{array}$ & Co-precipitation & In-situ polymerisation & $\begin{array}{c}\text { The PMMA nanocomposites consisting of 2, 4, } 6,8 \% \text { composition of LDH } \\
\text { was prepared by in situ polymerisation. The authors reported a random } \\
\text { dispersion of the nanofiller with a polymer matrix. There was an } \\
\text { observation of exfoliation of the nanofiller with partial intercalation at } \\
\text { higher content of the nanofiller. }\end{array}$ & [68] \\
\hline $\begin{array}{l}\text { Poly (ethylene terephthalate) } \\
\text { (PET)/CaAl-LDH and } \\
\text { MgAl-LDH }\end{array}$ & $\begin{array}{l}\text { The urea-assisted hydrothermal method was } \\
\text { used for preparation of MgAl-LDH, while the } \\
\text { co-precipitation method was used for } \\
\text { fabrication of CaAl-LDH. The co-precipitation } \\
\text { method was employed for MgAl-LDH with } \\
\text { stearic acid (MgAl-LDH-SA) }\end{array}$ & Solution blending method & $\begin{array}{l}\text { Scanning electron microscopy (SEM) and TEM showed homogenous } \\
\text { distribution of both CaAl-LDH and MgAl-LDH within a PET matrix. }\end{array}$ & [69] \\
\hline $\begin{array}{l}\text { Linear Low Density } \\
\text { Polyethylene/ZnAl-PDP LDH }\end{array}$ & High-energy ball milling & Melt blending and blowing & $\begin{array}{l}\text { The nanofiller in this study were modified by Potassium dodecyl } \\
\text { phosphate (PDP). SEM pictures showed uniform dispersion of the } \\
\text { nanofiller into the polymer matrix. The results were supported by XRD, } \\
\text { which indicated no diffraction peak for LDH. }\end{array}$ & [70] \\
\hline $\begin{array}{c}\text { Poly(methyl } \\
\text { methacrylate)/Co-Al LDH } \\
\text { (PMMA/LDH) }\end{array}$ & Instinctive self-assembly approach & Solvent blending technique & $\begin{array}{l}\text { The PMMA nanocomposites were prepared by the solvent blending } \\
\text { technique. The authors reported a wide dispersion of the nanofiller within } \\
\text { the PMMA matrix. There was an observation of exfoliation of the } \\
\text { nanofiller with partial intercalation at higher content of the nanofiller. }\end{array}$ & [71] \\
\hline $\begin{array}{l}\text { Linear Low Density } \\
\text { Polyethylene (LLDPE)/LDH }\end{array}$ & Anion exchange method & Solution intercalation method & $\begin{array}{l}\text { The nanofiller in this study was modified by dodecyl sulfate (DS). TEM } \\
\text { results showed uniform dispersion of the nanofiller into the polymer } \\
\text { matrix. Moreover, XRD and TEM results showed the formation of a } \\
\text { mixture of intercalated-exfoliated structures in the } \\
\text { LLDPE/LDH composites. }\end{array}$ & [72] \\
\hline
\end{tabular}




\section{Thermal Stability of Polymer/LDHs Nanocomposites}

Different studies have investigated the thermal stability of LDH/polymer nanocomposites [63,65,73-84]. Various thermal stability results (decrease or increase in the thermal stability of the nanocomposites) were recorded, depending on the LDH/polymer nanocomposites system. Lee et al. [84] reported an increase in the thermal stability of a composite that had the addition of the nanofiller into an ethylene vinyl acetate (EVA) matrix. In this study, an LDH nanofiller was modified with anionic surfactant, such as sodium dodecyl sulfate (DS), sodium dodecylbenzene sulfonate (DBS), and stearate (SA). When comparing the thermal stability (at 50\% weight loss) of the three modifications, $6 \mathrm{phr}$ of DS-LDH/EVA nanocomposites showed $19^{\circ} \mathrm{C}$ increment, while both the 6 phr of DBS-LDH/EVA and SA-LDH/EVA nanocomposites recorded $12{ }^{\circ} \mathrm{C}$ increase from the pristine EVA (Figure 4). However, Quispe-Dominguez et al. [63] reported a decrease in thermal stability with the incorporation of magnesium-aluminium layered double hydroxides modified with dodecylbenzene sulfonate (DBS). This was attributed to the catalytic effect of the modified nanofiller in the polymer matrix and as a result, reducing the thermal stability of the overall nanocomposites. Due to the two different mixing methods (viz: sonication-assisted masterbatch melt mixing and direct mixing) employed in this study for preparation of the nanocomposites, differences in thermal stabilities were observed, depending on the mixing method employed. It was reported that as much as the thermal stability decreases with the addition and increases in nanofiller content, the nanocomposites prepared by masterbatch melt mixing exhibited enhancement in thermal stability when compared with direct mixing, especially when considering same nanofiller content. For example, at $1.25 \%$ of the nanofiller, masterbatch melt mixing showed higher thermal stability than direct mixing at the same content. This behaviour was ascribed to a finer dispersion and better intercalation of the nanofiller during masterbatch melt mixing. Better dispersion and intercalation emphasize the fact that the PLA chains were more intercalated in the LDHs layers, in case of the PLA nanocomposites prepared by the SMA melt mixing method, resulting in an enhancement of thermal stability than the poorly dispersed and agglomerated nanofiller in case of the direct mixing method. Zoromba et al. [83] modified both copper-aluminium LDH and nickel-aluminium LDH with sodium stearate modifier and melt-mixed them with PP in an extruder. The authors reported better improvements in the thermal stability of the modified nickel-aluminium LDH when compared with neat PP, the unmodified nickel-aluminium LDH/PP, and copper-aluminium $\mathrm{LDH} / \mathrm{PP}$ nanocomposites. The improvement was attributed to better interfacial interaction between the nanofiller and the polymer matrix.

In this study, PMMA nanocomposites were prepared by solution mixing by adding flame resistant materials, such as intumescent flame retardant (IFR) (i) 1,2-Bis(5,5-dimethyl-1,3,2 -dioxyphospacyclOHexane phosphoryl amide) ethane (BPEA), (ii) graphene (reduced graphene oxide), and (iii) magnesium aluminium-layered double hydroxide modified with sodium dodecyl sulfate. It was reported that in the absence of IFR (BPEA), there was an increase in the thermal stability of PMMA nanocomposites with reduced graphene oxide (rGO), $\mathrm{LDH}$, and $\mathrm{LDH}+$ graphene as nanofillers when compared with pure PMMA. The synergistic effect of LDH and LDH+graphene showed more delay in the thermal decomposition of PMMA in comparison to PMMA/LDH and PMMA/graphene alone. This is an indication that the synergistic effect of nanofillers can form a better protective heat barrier and therefore delay the decomposition of the polymer, improving the thermal stability. Interestingly, it became apparent from the same study that the synergy of LDH and graphene further enhanced the thermal stability of PMMA/IFR composites. On the contrary, the synergistic effect of two LDH nanofillers i.e., MgAl-layered double hydroxides (MgAl-LDH) and NiCo-layered double hydroxides (NiCo-LDH) exhibited a decrease in the thermal decomposition of the nanocomposites, in comparison to neat epoxy (EP) at the initial decomposition temperature $\left(\mathrm{T}_{5 \%}\right)$ [85]. This was ascribed to the catalytic effect of the metals, which speed-up the polymer degradation. However, as much as the onset of degradation temperature decreased with the addition of the nanolayers, a combination of $2.5 \%$ of MgAl@NiCo exhibited a slightly higher thermal stability when compared with $2.5 \%$ of $\mathrm{MgAl}$ in the 
epoxy matrix. Therefore, a general remark can be made such that the synergy of LDH and nanofillers tend to produce a more compact char content than sole LDH in the polymer matrix.

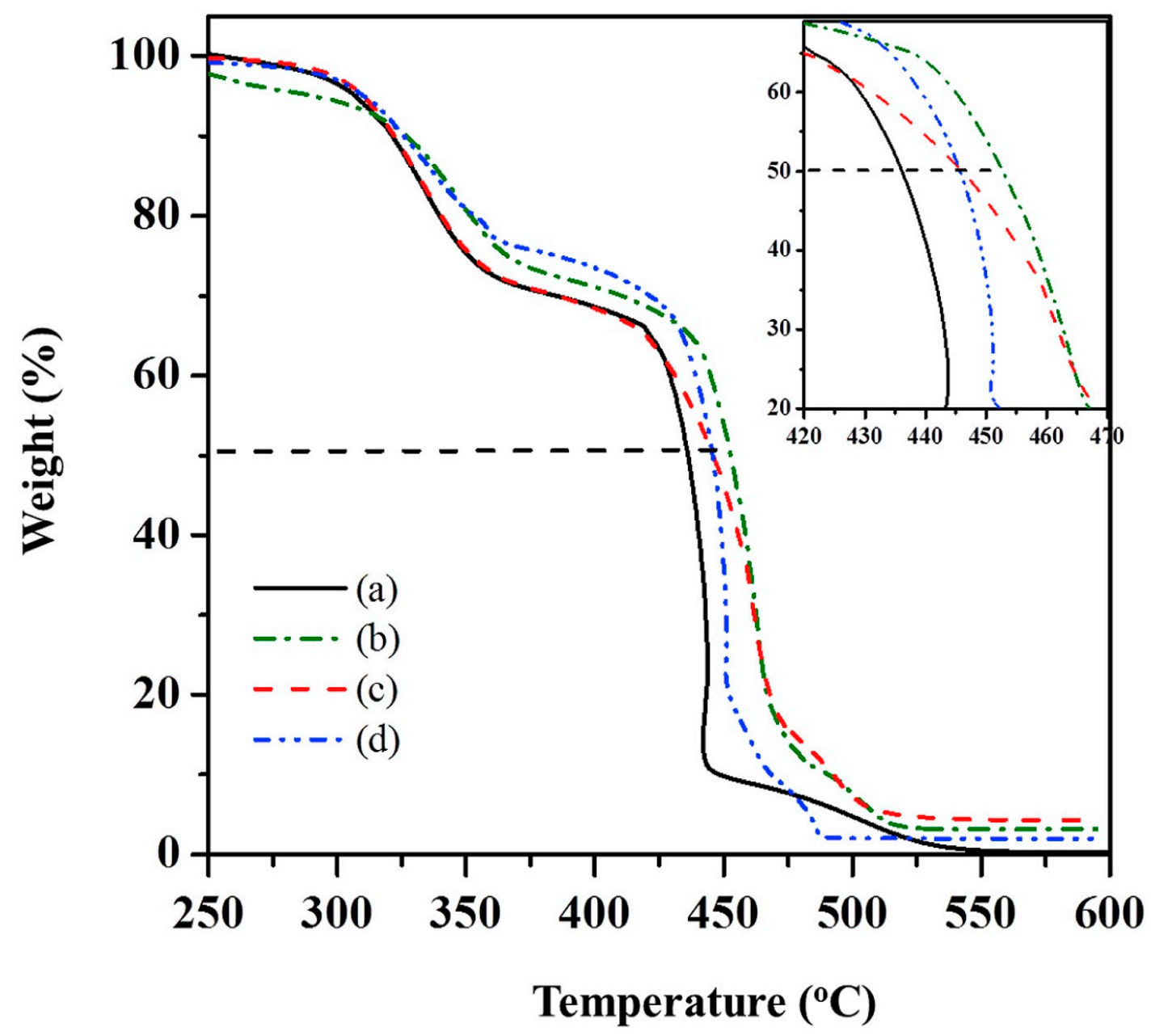

Figure 4. Thermogravimetric analysis curves of (a) neat EVA, (b) 6-phr DS-LDH/EVA, (c) DBS-LDH/EVA, and (d) SA-LDH/EVA. The zoomed area corresponds to the TGA curves at temperatures from 420 to $470{ }^{\circ} \mathrm{C}[84]$.

\section{Flammability Properties of Polymer/LDHs Nanocomposites}

Layered double hydroxide nanofillers have proven to be good flame-retardant materials for protection of polymers against heat [86]. A summarized version of the flame-retardant mechanism of LDH occurs through the endothermic process with the generation of water and metal oxide char. A number of authors have investigated the flammability properties of LDH/polymer and/or polymer/LDHs+another nanofiller in order to enhance the flammability resistance of the nanocomposites [85-89]. In most of these studies, the flammability properties of the nanocomposites were investigated by cone calorimetry and limiting oxygen index methods. Cone calorimetry parameters include: heat release rate (HRR), total heat release (THR), time to ignition (TTI), mass loss rate (MLR), and smoke production rate (SPR). Amongst the cone calorimetry parameters, the HRR has emerged as an important parameter since it measures the intensity of fire. A decrease in HRR peak symbolizes an improvement in flammability resistance of the material under investigation. Furthermore, an increase in limiting oxygen index (LOI) values is an indication of improvement in flammability of the nanocomposites. It was reported that the synergistic effect of LDHs with another nanofiller and/or an intumescent flame-retardant material significantly improved the flammability resistance of the polymer matrix when compared with LDH alone. Li et al. [87] investigated the flammability 
properties of the three LDHs (viz: MgFe-LDHs, MgAl-LDHs and MgAlFe-LDHs) incorporated into an EVA matrix. In this study, the LDHs nanofillers were produced from bittern by the co-precipitation method. Generally, there was a decrease in the heat release rate (HRR) of the EVA matrix with the addition of the LDHs nanofillers. The HRR peak of pristine EVA was recorded as $1645.8 \mathrm{~kW} / \mathrm{m}^{2}$. It became apparent that with the addition of the three LDHs, the HRR peaks were found to have reduced, i.e., EVA 1 (MgAl-LDHs) recorded a value of $222.65 \mathrm{~kW} / \mathrm{m}^{2}$, while EVA 2 (MgFe-LDHs) and EVA 3 (MgAlFe-LDHs) showed values of 311.87 and $286.96 \mathrm{~kW} / \mathrm{m}^{2}$, respectively. It can be concluded that the reduction in HRR is attributed to the formation of char residues in the presence of nanofillers, which acted as a protective barrier against heat. Since $\geq 90 \%$ of the layered double hydroxides must be modified in order to improve the dispersion of the nanoplatelets within the polymer matrix, it became apparent that the surfactants played a key role in the flammability properties of the resultant nanocomposite. Qiu et al. reported on the effect of surfactant (viz: sodium dodecyl sulfate (DDS) and stearic) on the flammability of PP and $\mathrm{Mg}_{3} \mathrm{Al}$ LDHs nanocomposites [88]. $\mathrm{Mg}_{3} \mathrm{AlLDH}$ were prepared with surfactants i.e., sodium dodecyl sulfate (DBS) and stearic by employing the aqueous miscible organic solvent modification technique, whereas the nanocomposites were prepared by the solvent mixing technique. The addition of both sodium dodecyl sulfate and stearic modified-LDH resulted in a decrease in the peak heat release rate (PHRR), with the stearic-based LDH nanofiller showing moderate improvement in the flame resistance of PP than the sodium dodecyl sulfate (DDS) modified-LDH. At both $20 \mathrm{wt} . \%$ of stearic modified-LDH and sodium dodecyl sulfate modified-LDH, the pHRR decreased by $61 \%$ and $58 \%$, respectively, in comparison to the neat PP. However, as much as there is an improvement in the flammability resistance of the LDHs/nanocomposites, there is a need for the formation of strong char layers during the process of burning. This can be achieved by combining two or more nanofillers with LDHs. Another study [85] reported on the flammability properties of the synergistic effect between NiCo-LDH and MgAl-LDH incorporated in an epoxy matrix. ZIF-67, a type of metal organic framework (MOF), was used as a precursor to tie up the $\mathrm{Co}^{2+}$ on the layered double hydroxide in order to convert more of it into NiCo-LDH platelets. Various weight percentages (wt.\%) of MgAl@NiCO (viz 2, 2.5 and 3) as well as MgAl-LDH (2.5 and 3 wt.\%.) were mixed with the epoxy matrix.MgAl@ZIF-67 was used as the benchmark to compare its flammability with neat $\mathrm{EP}, \mathrm{EP} / 2.5 \% \mathrm{MgAl}$, and $\mathrm{EP} / 2.5 \% \mathrm{MgAl} @ \mathrm{NiCo}$. The addition of $2.5 \% \mathrm{MgAl}$ reduced the PHRR when compared to neat EP, with the peak decreasing further with the addition of EP/2.5\% MgAl@NiCo (Figure 5). The reduction of PHRR in the presence of $2.5 \% \mathrm{MgAl} @ \mathrm{NiCo}$ was attributed to the formation of more compact char than the $\mathrm{MgAl}$, which can delay the entrance of heat and oxygen into the system and as a result, enhance the flammability resistance.

It was further proven that the addition of three metal LDHs improved the flammability resistance of the polymer matrix more than two metal LDHs [89]. The authors investigated the flammability properties of neat iPP, $6 \%$ Co-Al LDH, $6 \%$ Zn-AlLDH, $6 \%$ Co-Zn-AlLDH, and 10\% Co-Zn-Al LDH polypropylene nanocomposites. The three metal LDH nanocomposites showed better reduction in flammability than the two metal LDH nanocomposites, at the same content. The behaviour was attributed to the effective char formation for the $6 \% \mathrm{Co}-\mathrm{Zn}-\mathrm{Al} \mathrm{LDH}$ when compared with $6 \% \mathrm{Co}-\mathrm{Al}$ $\mathrm{LDH}$ and $6 \% \mathrm{Zn}-\mathrm{Al} \mathrm{LDH}$. This thermally stable char can prevent volatile gases/products from escaping out of the system and acting as a protective heat barrier, thereby preventing heat from entering the system, as a result improving the flammability resistance of the overall system. It is well known that a protective char will become fragile when more gaseous volatile products escape the system, which will provide easier passage of oxygen and heat into the material. Hence, it is important for flame retardant materials to form a stable and compact char in order to prevent the escape of volatiles gases and entering of heat into the system. Table 3 summarizes selective studies on the flammability of the polymer/LDH system. 
Table 3. Selective studies on the flammability properties of a polymer/LDHs system.

\begin{tabular}{|c|c|c|c|c|}
\hline Polymer/LDHs System & Synthesis of the Metal-LDH Nanofiller & $\begin{array}{l}\text { Preparation Method of the } \\
\text { Nanocomposites }\end{array}$ & Summary of the Flammability Results & References \\
\hline $\begin{array}{l}\text { Polypropylene (PP)/(AMO-LDHs) } \\
\text { and (O-CNT), } \\
\text { AMO = Aqueous miscible organic } \\
\mathrm{o}=\text { oxidized }\end{array}$ & Hydrothermal method & Solution mixing & $\begin{array}{l}\text { It was reported that the hybrid mixture of AMO-LDH-OCNT improved the } \\
\text { flammability resistance of PP better than AMO-LDHs alone. A synergy } \\
\text { fabricated from } 10 \text { wt.\% AMo-LDH+1 wt.\% oCNT showed } 40 \% \text { reduction in } \\
\text { peak heat release rate (pHRR) when compared with } 20 \text { wt. } \% \text { AMO-LDH } \\
\text { ( } 31 \% \text { reduction in pHRR). }\end{array}$ & [90] \\
\hline $\begin{array}{l}\text { Polypropylene (PP)/LDHs and PP/M-LDHs, } \\
\mathrm{M}-\mathrm{LDHs}=\mathrm{Mg}-\mathrm{Al}-\mathrm{H}_{2} \mathrm{PO}_{4}^{-} \mathrm{LDHs}\end{array}$ & $\begin{array}{l}\text { An ion exchange method was used for } \\
\text { fabrication of dihydrogen phosphate } \\
\text { intercalation }\left(\mathrm{Mg}-\mathrm{Al}^{-} \mathrm{H}_{2} \mathrm{PO}_{4}^{-}\right)\end{array}$ & Melt mixing by using an extruder & $\begin{array}{l}\text { The addition of LDH (Mg-Al- } \mathrm{CO}_{3}{ }^{-2} \mathrm{LDH} \text { ) reduced the pHRR from } \\
1032 \mathrm{~kW} / \mathrm{m}^{2} \text { (pristine PP) to } 837 \mathrm{~kW} / \mathrm{m}^{2} \text { with the pHRR decreasing } \\
\left(534 \mathrm{~kW} / \mathrm{m}^{2}\right) \text { further with the addition M- } \mathrm{LDHs}\left(\mathrm{Mg}-\mathrm{Al}^{-} \mathrm{H}_{2} \mathrm{PO}_{4}^{-} \mathrm{LDHs}\right) \text {. }\end{array}$ & [81] \\
\hline $\begin{array}{l}\text { Polypropylene }(\mathrm{PP}) / \mathrm{APP}-\mathrm{LDH} \text { and } \mathrm{ZB}, \\
\mathrm{APP}=\text { Ammonium polyphosphate, } \\
\mathrm{ZB}=\text { Zinc borate }\end{array}$ & 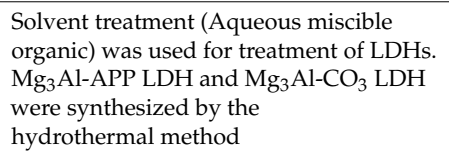 & Solvent mixing & $\begin{array}{l}\text { The addition of } 10 \text { and } 20 \mathrm{wt} . \% \text { of APP-LDH resulted in an improvement in } \\
\text { flammability resistance in comparison to carbonate } \mathrm{LDH}\left(\mathrm{Mg}_{3} \mathrm{Al}^{-\mathrm{CO}} \mathrm{O}_{3} \mathrm{LDH}\right) \text {. } \\
\text { The synergistic effect of } \mathrm{ZB} \text { and APP-LDH improved the flammability } \\
\text { resistance further in comparison to APP-LDH alone. }\end{array}$ & [91] \\
\hline $\begin{array}{l}\text { Thermoplastic } \\
\text { polyurethane/LDHs-graphene oxide } \\
\text { (TPU/LDHs-GOs) }\end{array}$ & $\begin{array}{l}\mathrm{NO}_{3}^{-} \text {-LDHs-GO was fabricated by the } \\
\text { co-precipitation method }\end{array}$ & Melt mixing method & 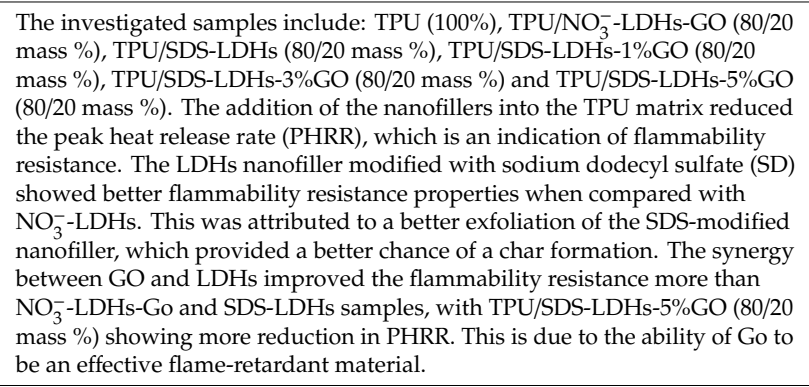 & [92] \\
\hline $\begin{array}{l}\text { Acrylonitrile-Butadiene-Styrene/(CaMgAl } \\
\text {-Layered Double Hydroxides) } \\
\text { (CaMgAl-LDHs) }\end{array}$ & $\begin{array}{l}\text { CaMgAl-LDHs was fabricated by } \\
\text { Co-precipitation method. Borated } \\
\text { CaMgAl-LDHs was prepared by } \\
\text { dissolving CaMgAl-LDHs into boric acid } \\
\text { solution. In order to form } \\
\text { O-CaMgAl-LDHs, B-CaMgAl-LDHs was } \\
\text { dissolved in sodium oleate solution. }\end{array}$ & Melt blending by two-roll mix & $\begin{array}{l}\text { The addition of 10, } 20,30 \text { and } 40 \% \text { of O-CaMgAl-LDHs increased with the } \\
\text { addition and increasing in o-CaMgAl-LDHs content. The synergistic of } \\
\text { O-CaMgAl-LDHs, ammonium polyphosphate (APP) and graphite (EG) } \\
\text { showed higher values than O-CaMgAl-LDHs. }\end{array}$ & [93] \\
\hline
\end{tabular}




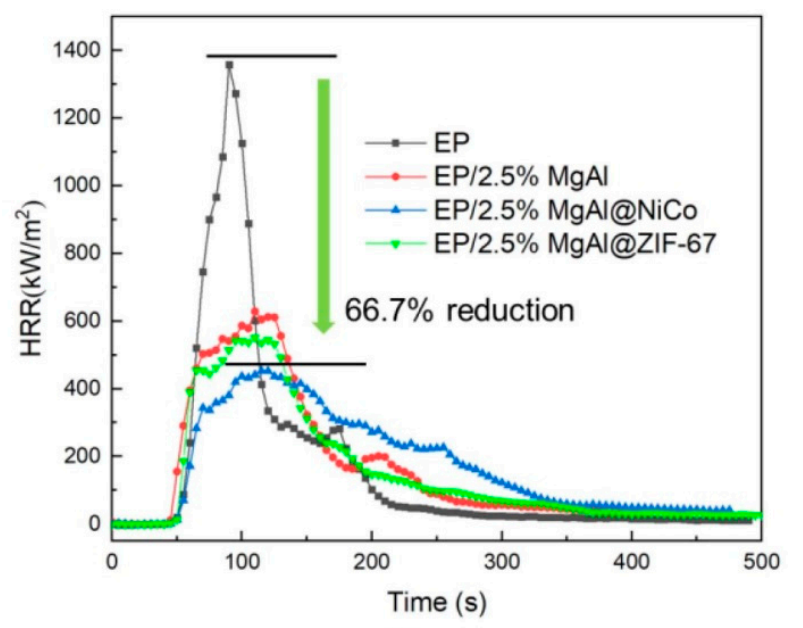

Figure 5. Heat release rate (HRR) of neat, EP, EP/2.5\% MgAl, EP/2.5\% MgAl@NiCo, EP/2.5\% MgAl@ZIF-67 [85].

\section{Barrier Properties of Layered Double Hydroxides (LDH)}

Layered double hydroxides (LDHs) are usually combined with polymer matrices to form films with good gas barrier properties, for applications in food packaging and encapsulation of electronic devices [94,95]. LDHs consist of crystalline layered structures [96-99] that induce gas barrier properties by increasing the diffusion length of gases, therefore resisting permeating gases in the resultant polymer film. The development of organic-inorganic composite materials with gas barrier properties, e.g., $\mathrm{LDH} /$ polymer films, still faces a few challenges. One of them is that the diffusion of gas molecules is only suppressed in the direction of the film, i.e., the gas molecules flowing parallel to the inorganic structural layers are not resisted [100-102]. In such a case, the gas barrier properties of the film are usually improved by increasing the content of the crystalline layered structures. However, the loading with these inorganic crystalline structures reduces the flexibility and toughness of the barrier materials. Another challenge is that the incorporation of highly oriented inorganic structural layers into polymer matrices also causes polymer aggregation. This aggregation creates voids through which gas molecules permeate easily. This results in a film with compromised gas barrier properties [103]. In a quest to curb the challenges faced by the development of LDH-based gas barrier materials, considerable efforts have been directed towards developing the structure of LDHs. Dou et al. [104] discovered that the incorporation of plate-like LDH (P-LDH) into a polymer matrix, e.g., chitosan (CTS), improved the oxygen barrier properties of the resultant films. However, the challenge was that the oxygen barrier properties were not that good for very thin films. Hence, in another study [95], the authors converted the LDH with a plate-like structure to one with a hierarchical structure (H-LDH). The oxygen transmission rate of the resultant H-LDH/CTS films was reduced by almost $37 \%$ when compared to that of the original P-LDH/CTS films, indicating that the structural conversion of the LDHs improved their gas barrier properties. The synthesis of $\mathrm{H}-\mathrm{LDH}$ was performed via the continuous calcination-rehydration treatment of P-LDH. The resultant H-LDH was then used as a scaffolding material for the fabrication of chitosan multi-layered films via an alternate spin-coating process. This process led to the formation of (H-LDH/CTS $)_{n}$ films with excellent oxygen barrier properties. The (H-LDH/CTS $)_{n}$ films exhibited an oxygen transmission rate (OTR) that was below the detection limit of commercial instruments $\left(<0.005 \mathrm{~cm}^{3} / \mathrm{m}^{2}\right.$ day atm).This was attributed to the capabilities of H-LDH to resist the migration of oxygen molecules from multiple directions by creating a longer diffusion pathway. Large amounts of oxygen molecules were also absorbed by the large surface area of the H-LDH. The large surface area of the H-LDH filled-in all the gaps between H-LDH and the polymer matrix, thus closing-up the space for oxygen permeation [95]. During the development of LDH/polymer gas barrier films, improving the durability of the films is quite important, especially for applications such as food packaging and encapsulation of electronic devices. In order to achieve this, $\mathrm{LDH} /$ polymer films with 
self-healing properties are designed and fabricated. This results not only in a film with excellent gas barrier properties, but also one with the ability to repair itself after damage by external stimuli. In a

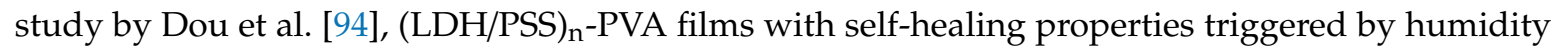
were fabricated via the layer-by-layer assembling of layered double hydroxide nanoplatelets and poly(sodium styrene-4-sulfonate) (PSS), followed by the subsequent incorporation of poly(vinyl alcohol) (PVA). The even distribution of the highly oriented LDH nanoplatelets in the film was responsible for the resistance of permeating gases by creating a long diffusion pathway. The PVA was responsible for the humidity-stimulated self-healing properties of the films. When the films were exposed to humidity after the development of the stimuli crack, the water molecules triggered the formation of hydrogen bonds among the hydroxyl groups of PVA, thus causing the stimuli crack to close. Hydrogen is usually used as an alternate fuel to fossil fuels because its combustion only produces water, which implies less air pollution. However, amongst many other methods of storing hydrogen, LDHs have been considered as the best substances for the storage of hydrogen gas. This is achieved through the conversion of LDHs into microporous materials through intercalation with other anionic substances. Huang and Cheng [105] intercalated Li-Al layered double hydroxides with various organic anions via a co-precipitation method. The maximum hydrogen absorption per micropore surface area of the LDHs prepared in this study was higher than that of metal organic frameworks (MOFs) reported in the literature, hence confirming the microporous nature of the prepared LDHs. Table 4 summarizes selective studies on the barrier properties of polymer-LDHs nanocomposites. 
Table 4. Selective studies for the preparation and barrier properties of polymer-LDHs nanocomposites.

\begin{tabular}{|c|c|c|c|c|}
\hline Polymer/LDHs System & $\begin{array}{l}\text { Synthesis of the Metal-LDH } \\
\text { Nanofillers }\end{array}$ & $\begin{array}{l}\text { Preparation Method of the } \\
\text { Nanocomposites }\end{array}$ & Summary of the Resultant Barrier Properties & References \\
\hline $\begin{array}{l}\text { Cellulose nanofibrils } \\
(\mathrm{CNFs}) / \mathrm{MgAl}-\mathrm{CO}_{3}-\mathrm{LDHs}\end{array}$ & $\begin{array}{l}\text { LDHs were synthesized via the } \\
\text { hydrothermal method }\end{array}$ & $\begin{array}{l}\mathrm{CNFs} / \mathrm{MgAl}-\mathrm{CO}_{3}-\mathrm{LDHs} \text { with different } \mathrm{LDH} \\
\text { ratios were prepared by a } \\
\text { filtering/evaporation process that induced } \\
\text { barrier and strengthening properties in the } \\
\text { composite films. }\end{array}$ & 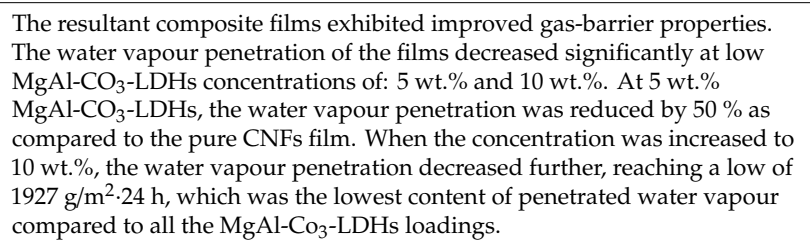 & [106] \\
\hline $\begin{array}{l}\text { Nitrile butadiene rubber } \\
\text { (NBR)/polyvinyl pyrrolidone } \\
\text { modified ultrathin LDH } \\
\text { nanoplatelets (U-mLDHs). }\end{array}$ & $\begin{array}{l}\text { The U-mLDHs nanoplatelets were } \\
\text { prepared by a slightly improved } \\
\text { co-precipitation method. }\end{array}$ & $\begin{array}{l}\text { The NBR/U-mLDH composites were } \\
\text { prepared by a layer-by-layer spin-coating } \\
\text { assembly technique. }\end{array}$ & $\begin{array}{l}\text { The oxygen transmission rate (OTR) of the films with a higher aspect ratio, } \\
\text { (U-mLDH/NBR })_{30} \text {, was reduced by } 92.2 \% \text { compared with the pure NBR film. } \\
\text { The improved gas barrier properties were due to the decreased diffusion } \\
\text { pathway of the oxygen molecules. The free space between the U-mLDH and } \\
\text { NBR was due to the large aspect ratio of the U-mLDH and the improved } \\
\text { interfacial adhesion at the LDH-polymer interface. }\end{array}$ & [107] \\
\hline $\begin{array}{l}\text { Linear low density polyethylene } \\
\text { (LLDPE)/LDH composite films. }\end{array}$ & $\begin{array}{l}\text { LDH intercalated with an aliphatic } \\
\text { long-chain anion was prepared by a } \\
\text { single pot high-energy balling } \\
\text { method. }\end{array}$ & $\begin{array}{l}\text { The films were prepared by melt blending } \\
\text { and blow processing. }\end{array}$ & $\begin{array}{l}\text { The water vapour barrier properties of the LLDPE composite films with } 1 \% \\
\text { LDH were enhanced by } 60.36 \% \text {. This was attributed to the LDH inducing a } \\
\text { longer diffusion pathway for the water molecules. }\end{array}$ & [70] \\
\hline $\begin{array}{l}\text { Poly(vinyl alcohol)(PVA)/hydrid } \\
\text { layered double hydroxides } \\
\text { (LDHs)-reduced grapheme oxide } \\
\text { (rGO) (LDH-rGO). }\end{array}$ & $\begin{array}{l}\text { MgAl-LDH-rGO hybrids were } \\
\text { prepared by the co-precipitation } \\
\text { method. }\end{array}$ & $\begin{array}{l}\text { The PVA/LDH-rGO hybrid films were } \\
\text { prepared by the solution casting method. }\end{array}$ & $\begin{array}{l}\text { The oxygen transmission rate (OTR) of PVA/LDH-rGO films was decreased } \\
\text { by } 86 \% \text { at } 1 \% \text { LDH-rGO loading. The improved barrier properties were } \\
\text { attributed to the uniformly dispersed LDH-rGO hybrids in PVA. }\end{array}$ & [108] \\
\hline
\end{tabular}




\section{Mechanical Properties of Polymer-LDHs Systems}

Mechanical properties are used to determine the strength and ductility of polymer nanocomposites. The mechanical properties of LDH-based polymer nanocomposites were investigated by different studies [109-114]. Numerous factors were found to affect the mechanical properties of LDHs nanocomposites, including the content of LDHs, the type of LDHs, polymer matrix, dispersion of LDH in polymer matrix, and the preparation method. Botan et al. investigated the mechanical properties of polyamide 6 incorporated with two types of LDHs (viz Zn/Cr-L and Zn/Cr-P, with Zn = Zinc, $\mathrm{Cr}=$ Chromium, $\mathrm{L}=$ lauric acid and $\mathrm{P}=$ palmitic acid) [109]. The LDHs nanocomposites were fabricated by in situ polymerization with various composition of the filler (viz 1, 2, and $3 \mathrm{wt.} \%$ ). Mechanical properties of nanocomposites were investigated with tensile tester. The modulus of elasticity (E) decreased at lower content of $\mathrm{Zn} / \mathrm{Cr}$-L i.e., $1 \mathrm{wt} . \%$, with the $\mathrm{E}$ values increasing at higher compositions of $\mathrm{Zn} / \mathrm{Cr}-\mathrm{L}$ (viz 2, and $3 \mathrm{wt} . \%$ ). The decrease in $\mathrm{E}$ values at lower content was attributed to the plasticizing effect due to the absorption of the water at lower content. Similarly, the addition of $\mathrm{Zn} / \mathrm{Cr}-\mathrm{P}$ increased the $\mathrm{E}$ values of the polyamide 6 nanocomposites in all investigated filler composition. The optimum composition for both fillers was obtained at $2 \mathrm{wt} . \%$, with the $\mathrm{Zn} / \mathrm{Cr}-\mathrm{P}$ nanofiller showing higher $\mathrm{E}$ values when compared with $\mathrm{Zn} / \mathrm{Cr}-\mathrm{L}$ counterpart. This was attributed to the bilayer structures, which allowed an efficient stress-transfer. The effect of stearate intercalated LDH on the properties of PU was investigated in the literature [110]. The polyurethane (PU)/Stearate-intercalated LDH was fabricated by solution intercalation. There was an enhancement in tensile strength (TS) with the incorporation of stearate-LDH (viz 1, 3, 5, and $8 \mathrm{wt} . \%$ ) into PU matrix, when compared with the neat PU. The tensile strength was observed to increase with decreasing in stearate-LDH nanoparticles content. A higher tensile strength (TS) at $1 \mathrm{wt} . \%$ of stearate-LDH was ascribed to a better exfoliation at this content. There was a reported increase in elongation at break with addition of stearate-LDH nanoparticles into the PU. The behaviour was ascribed to the plasticization of the alkyl chain intercalated into the LDH in the PU/stearate-LDH system. Feng and co-workers investigated the properties of the LDHs reinforced peroxide-cured acrylonitrile butadiene rubber [111]. The LDHs were organically modified with sodium dodecylbenzene (SDBS) and sodium styrene sulfonate (SSS). The LDH modified with sodium styrene sulfonate (SSS) composites showed better mechanical properties than neat acrylonitrile butadiene rubber (NBR) and LDH modified with sodium dodecylbenzene composites. This behaviour was attributed to a better chemical bond between the organically modified LDHs sodium styrene sulfonate (SSS) and NBR. Based on the above study, it became apparent that the type of organic modifier may influence the overall properties of the LDHs-polymer nanocomposites. Suresh and co-workers [112] investigated the Co-Al layered double hydroxide reinforced polystyrene nanocomposites. In this study, Co-Al layered double hydroxide was organically modified with sodium dodecyl sulfate (SDS) and the composites were prepared by melt compounding. It was observed that at $1 \mathrm{wt} . \%$ of $\mathrm{Co}-\mathrm{Al} \mathrm{LDH}$ nanocomposite, there is an enhancement in both tensile and tensile modulus when compared with neat PS and 3, 5 as well as $7 \mathrm{wt} . \%$ Co- Al LDH nanocomposites, respectively (Figure 6). At lower content, i.e., $1 \mathrm{wt} . \%$, there is a better exfoliation of the nanoparticles in the PS matrix as well as enhanced interfacial interaction between the two phases, which resulted in better mechanical properties. At higher content of the nanofiller, there is a probability of agglomerated Co-Al LDH, which formed defects, and as a result lowering the mechanical properties. Table 5 summarizes selective studies on the mechanical properties of LDH-polymer nanocomposites. 


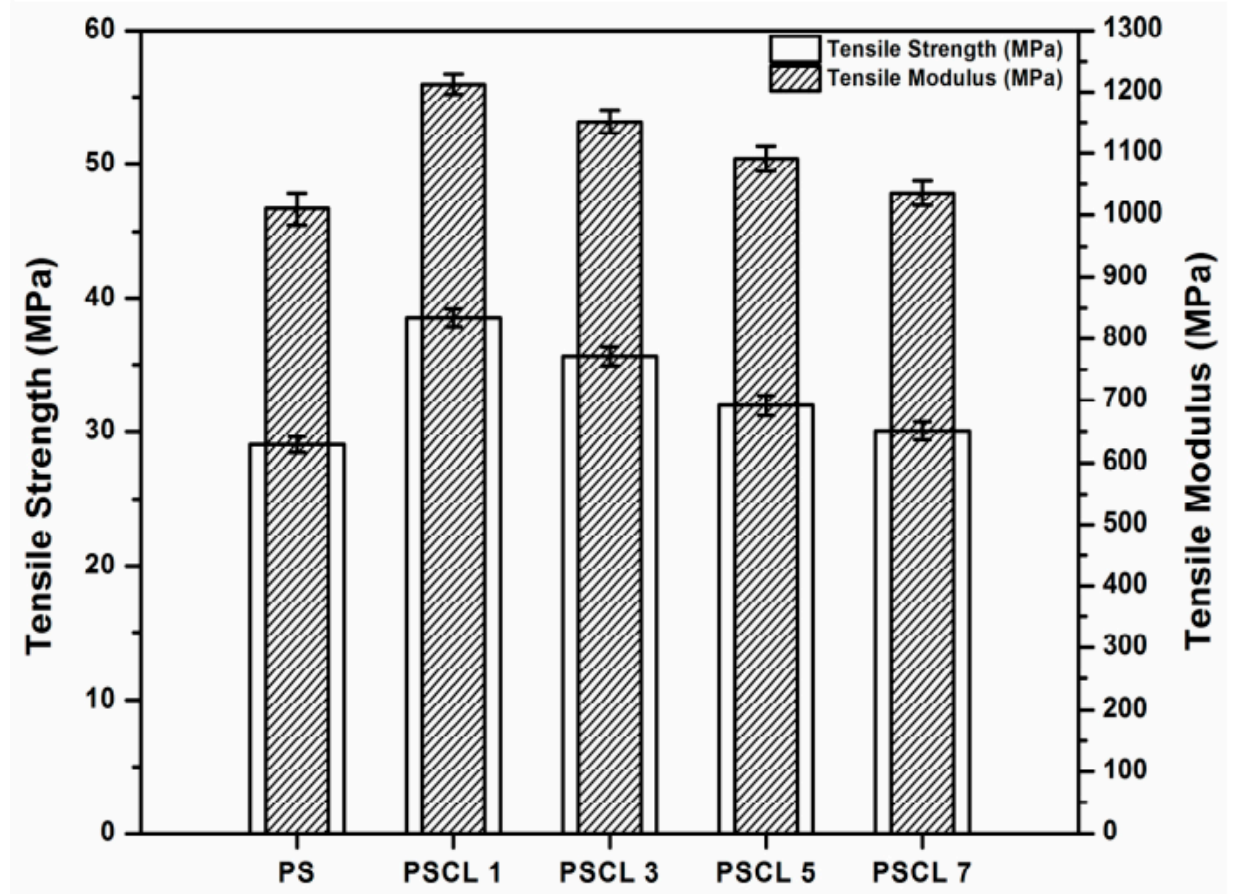

Figure 6. Tensile strength and tensile modulus of polystyrene and its Co-Al layered double hydroxide nanocomposites [112].

Table 5. Selective studies on mechanical properties of LDH-polymer nanocomposites.

\begin{tabular}{|c|c|c|c|}
\hline Polymer-LDHs Nanocomposites & $\begin{array}{l}\text { Preparation of Polymer-LDHs } \\
\text { Nanocomposites }\end{array}$ & Summary of the Mechanical Properties & References \\
\hline $\begin{array}{c}\text { Epoxy }(\mathrm{EP}) / \mathrm{Mg}-\mathrm{Al} \mathrm{LDH} \\
\text { intercalated with ammonium } \\
\text { alcOHol polyvinyl } \\
\text { phosphate (AAPP) }\end{array}$ & Solution intercalation & $\begin{array}{l}\text { The addition of } 10 \text { and } 20 \text { mass } \% \text { of intercalated LDHs } \\
\text { into EP showed higher tensile strength than neat EP. }\end{array}$ & [113] \\
\hline $\begin{array}{c}\text { Poly( }(\varepsilon \text {-caprolactone) } \\
\text { (PCL)/Silver-LDH (Ag-LDH). } \\
\text { LDH = Mg-Al LDH } \\
\text { Type of silver-LDHs used are: } \\
\text { Ag-LDHs@PDA } \\
\text { PDA = polydopamine } \\
\text { Ag-LDHs@TA-Fe (III) } \\
\text { TA = tannic acid } \\
\text { Fe (III) = Iron (III) } \\
\text { Ag-LDHs (PVP) } \\
\text { PVP = pyrrolidone }\end{array}$ & Solution casting method & $\begin{array}{l}\text { It was reported that when the composition of Ag-LDHs } \\
\text { was } 0.5 \text { wt. } \% \text {, the tensile strength of the } \\
\text { Ag-LDHs@TA-Fe(III)/PCL system decreased by } 11 \% \text {, } \\
\text { while the LDHs@PDA/PCL nanocomposite reduced by } \\
4 \% \text { when compared with neat PCL. The } 0.5 \text { wt. } \% \text { of } \\
\text { Ag-LDHs(PVP) showed } 26 \% \text { reduction in } \\
\text { tensile strength. }\end{array}$ & [114] \\
\hline $\begin{array}{c}\text { Cellulose nanofibrils }(\mathrm{CNF}) / \mathrm{Mg} \\
\mathrm{Al}-\mathrm{CO}_{3}-\mathrm{LDHs}\end{array}$ & Filtering/evaporation method & $\begin{array}{c}\text { According to the study, } 5 \mathrm{wt} . \% \text { of the LDH showed } \\
\text { higher tensile strength in comparison to neat CNF, 10, } 15 \\
\text { and } 25 \% \text { of LDHs. Higher tensile strength at low content } \\
\text { was ascribed to a better dispersion of the nanofiller in } \\
\text { a matrix. }\end{array}$ & [106] \\
\hline $\begin{array}{l}\text { Poly(ethylene-co-vinyl alcOHol) } \\
\text { (EVAL)/LDHs, } \\
\text { LDH was organically } \\
\text { modified with: Stearate (SA), } \\
\text { to form SA-LDH }\end{array}$ & Melt compounding & $\begin{array}{l}\text { Mechanical properties of EVAL/LDH composites were } \\
\text { compared with neat EVAL. The authors reported that the } \\
\text { charpy notched impact strength of the composites was } \\
\text { twice that of the neat EVAL polymer. This was attributed } \\
\text { to the extensive internal micro-cavitation of the highly } \\
\text { dispersed and randomly dispersed LDH platelets during } \\
\text { impact loading. The large surface area created by the } \\
\text { micro-cavitation enhanced the requisite energy } \\
\text { dissipation mechanism. }\end{array}$ & [115] \\
\hline
\end{tabular}




\section{Selective Applications of Different Polymer-LDHs Systems}

Layered double hydroxides nanocomposites have been prepared for various applications including energy, food packaging, water purification, gas sensing, biomedical, flame retardant, and agricultural applications [68,116-119]. Qin and co-workers investigated the LDHs nanocomposites based on PANI/ZnTI-LDHs for sensing ammonia gas $\left(\mathrm{NH}_{3}\right)$ [116]. The LDHs (ZnTi-LDHs) nanofiller was prepared by hydrothermal method and the nanocomposites were fabricated by in situ chemical oxidative polymerization. The ability of the $\mathrm{LDH}$ nanocomposites in sensing $\mathrm{NH}_{3}$ was compared with neat PANI and ZnTi-LDHs. The LDHs nanocomposites were found to exhibit a significant $\mathrm{NH}_{3}$ sensing ability with good lengthy stability when compared with neat polymer and LDHs, respectively. The results were ascribed to a more-loose architecture structure of the nanocomposite, which improves the adsorption site as well as facilitation of the gas adsorption. The system consisting of sulfonated polyaniline (SPAN) reinforced with graphene oxide (GO)-LDHs was investigated for extraction phthalates in drinking water and distilled herbal beverages [117]. The study compared the extraction efficiency of GO-LDH@SPAN nanocomposite with LDH and GO-LDH for extraction of phthalates from aqueous solution. The extraction efficiency of the LDH@SPAN nanocomposite for phthalate was higher than neat LDH and GO-LDH, with LDH showing lower extraction than GO-LDH. The reason LDH showed lower extraction for phthalates was due to a possible weak hydrogen bond between LDH and phthalates. The higher extraction efficiency of phthalates by GO-LDH was attributed to a $\pi-\pi$ bond between GO and aromatic ring of phthalates. The GO-LDH@SPAN nanocomposite showed higher extraction of the analyte because SPAN can promote more $\pi-\pi$ interaction with the phthalate. Furthermore, as SPAN has $\mathrm{O}=\mathrm{S}=\mathrm{O}$ in the matrix, it presents more active sites for extraction of the analytes. PMMA/Mg- Al LDH nanocomposites was fabricated by in situ polymerization for a possible packaging application [68]. Two key results were significant in determining a possible packaging application, i.e., thermal stability and gas permeability. The fabricated nanocomposites were reinforced with 2, 4, and $8 \%$ of $\mathrm{Mg}$-Al LDH. There was a decrease in the oxygen flow rate of the nanocomposites in comparison to neat PMMA. This behavior was attributed to a dispersion of LDH in a polymer matrix, which acts as protective barrier for oxygen permeability; as for neat PMMA, the presence of voids resulted in oxygen penetration within the matrix. The addition of the LDH into the PMMA enhanced the thermal stability of PMMA matrix when compared with neat PMMA. The reduction in oxygen permeability and the enhancement in thermal stability of the PMMA/Mg-Al LDH system suggest that the nanocomposite may be suitable for packaging application.

In recent times, the demand for highly flexible, durable, and lightweight piezoelectric nanogenerators has led to the fabrication of piezoelectric and dielectric electrospun nanofabrics of poly (vinylidene fluoride) (PVDF)/Ca-Al LDH composites. During the fabrication of the PVDF/Ca-Al LDH composite nanofabrics, the Ca Al- LDH nanosheets were first synthesized via a modified coprecipitation method before they were incorporated as filler into the PVDF matrix. The composite nanofabrics of PVDF/Ca-Al LDH were finally obtained via the electrospinning of the composite solutions. The synergy between the PVDF-LDH interaction and the in situ stretching, which was attributed to the electrospinning, enhanced the nucleation of the electroactive $\beta$ phase up to $82.79 \%$. This was an indication that these composite nanofabrics are suitable for piezoelectric-based nanogenerators. The hand slapping and frequency-dependent mechanical vibration mode methods showed that the piezoelectric performance of the PVDF/Ca-Al LDH composite nanofabrics can reach a maximum open circuit output voltage of 4.1 and $5.72 \mathrm{~V}$. The composite nanofabrics also had a high dielectric constant and a low dielectric loss, which were attributed to high interfacial polarization at low frequencies with increasing LDH loading. This showed that these materials have the potential to be used in electronic devices [118].

Wang et al. [119] prepared $\mathrm{Zn} \mathrm{Al} \mathrm{-LDH/polycaprolactone} \mathrm{(PCL)} \mathrm{nanocomposites} \mathrm{for} \mathrm{use} \mathrm{in} \mathrm{drug}$ delivery systems. The $\mathrm{Zn} \mathrm{Al-LDH}$ was synthesized via the co-precipitation method while the ZnAl -LDH/PCL nanocomposites were prepared by the solution intercalation method. The ZnAl-LDH/PCL composite nanofabrics exhibited a higher weight loss and drug release amount when compared to neat 
PCL. The drug release kinetics followed the first-order kinetic model for the Zn Al-LDH/PCL composites, indicating that the drug release was content-dependent. However, for the neat PCL, the drug release kinetics followed the Ritger-Peppas kinetic model, indicating that the release followed the Fikian mechanism. Table 6 summarizes selective studies on the applications of LDH-polymer nanocomposites.

Table 6. Summary of selective studies on the application of LDH-polymer nanocomposites.

\begin{tabular}{|c|c|c|c|}
\hline Polymer-LDH System & $\begin{array}{l}\text { Preparation Method for the } \\
\text { Nanocomposites }\end{array}$ & Intended Application & References \\
\hline $\begin{array}{l}\text { Poly(lactide-co-glycolic acid) } \\
\text { (PLGA)/Mg Al-LDH }\end{array}$ & $\begin{array}{l}\text { Solution mixing and casting into } \\
\text { thin films }\end{array}$ & Drug delivery applications & [120] \\
\hline $\begin{array}{l}\text { Polypropylene-grafted maleic } \\
\text { anhydride (PP-g-MA)/Dye } \\
\text { structure-intercalated layered double } \\
\text { hydroxide (d-LDH) }\end{array}$ & co-precipitation & Flame retardant applications & [121] \\
\hline $\begin{array}{l}\text { Waterborne polyurethane (WPU)/LDH } \\
\mathrm{LDH}=\left(\mathrm{M}_{\mathrm{x}} \mathrm{Al} / \mathrm{CO}_{3}{ }^{2-}, \mathrm{M}=\mathrm{Mg} \text { and } / \text { or }\right. \\
\mathrm{Zn} \text {, and } \mathrm{x}=2,3 \text { and } 4)\end{array}$ & $\begin{array}{l}\text { Solution mixing and casting into } \\
\text { thin films }\end{array}$ & Coatings applications & [122] \\
\hline Chitosan (CS)/NiFe-LDH & $\begin{array}{l}\text { Low-saturation } \\
\text { co-precipitation method. }\end{array}$ & Catalytic applications & [123] \\
\hline $\begin{array}{l}\text { Polylactic acid (PLA)/Intumiscent flame } \\
\text { retardant (IFR)/Phosphotungstic acid } \\
\text { intercalated Mg Al-LDH (PWA-LDH) }\end{array}$ & $\begin{array}{l}\text { Melt blending and hot pressing } \\
\text { into films }\end{array}$ & Flame retardant applications & [124] \\
\hline $\begin{array}{l}\text { CoNiMn-LDH/Polypyrrole } \\
\text { (PPy)/Reduced graphene oxide (RGo) }\end{array}$ & $\begin{array}{l}\text { One-step route in which the } \\
\text { co-precipitation reaction of metal ions } \\
\left(\mathrm{Co}^{2+}, \mathrm{Ni}^{2+} \text { and } \mathrm{Mn}^{2+}\right) \text { was used to } \\
\text { prepare } \mathrm{LDH} \text { and the polymerization } \\
\text { of pyrrole (Py) was used to prepare } \\
\text { PPy. Modified Hummer's method } \\
\text { was used to prepare graphene oxide }\end{array}$ & Electrocatalytic applications & [125] \\
\hline $\begin{array}{l}\text { Isotactic polypropylene } \\
\text { (iPP)/ZnAl-LDH }\end{array}$ & Solvent mixing method & Flame retardant applications & [89] \\
\hline Polystyrene (PS)/MgAl -LDH & Solution mixing & $\begin{array}{l}\text { Removal of } \mathrm{Cd}^{2+} \text { ions from } \\
\text { aqueous media }\end{array}$ & [126] \\
\hline Poly(vinyl chloride) (PVC)/MgAl LDH & Solution intercalation method & Biomedical applications & [127] \\
\hline
\end{tabular}

\section{Conclusions and Future Recommendations}

Layered double hydroxides (LDHs) have been the nanofiller of choice in terms of improving the flame retardancy and barrier properties of polymer matrices. However, the improvement in properties of the LDHs/polymer systems depended on the dispersion of the nanofiller within the polymer matrices. It is apparent that LDHs nanofillers in most cases has been organically modified in order to improve the exfoliation of the nanofillers in polymer matrices. The dispersion of LDHs/polymer system varied depending on the method of preparation, type of modifier, and the type of LDHs/polymer system. Generally, there was an improvement in the flammability resistance of polymer matrices with the addition of LDHs with different compositions. The flammability resistance improved more in the presence of LDHs and other flame-retardant fillers. The synergy of LDHs and nanofillers improved the flame retardancy more because it is able to form a strong and compact char layer, which can inhibit the entry of heat into the system, thereby improving the overall flammability resistance of the system. The gas barrier properties of LDH/polymer films were dependent on the orientation and distribution of the LDH nanoplatelets. Highly oriented and evenly distributed LDH nanoplatelets created a resistance for the migration of gas molecules from multiple directions by increasing the diffusion pathway of the permeating gases. The intercalation of LDHs with organic anions altered their gas barrier properties by converting the LDHs into microporous materials. However, although LDH improved the properties of various polymer matrices, there is still a huge gap in terms of the thermal conductivity of the LDHs-polymer nanocomposites. In the past, LDHs nanofillers were fabricated with conductivity polymers such as polyaniline and polypyrrole; however, there are a few studies investigating the thermal conductivity of LDHs in combination with well-known conductive fillers such as expanded graphite, carbon nanotubes, carbon black, and carbon fiber to widen the applications 
of LDHs nanocomposites. The fabricated hybrid LDH/conductive filler/polymer nanocomposite may be used in applications such as flame retardant, supercapacitors, and batteries. Furthermore, there is also less investigation on the effect of LDHs in natural fiber reinforced biopolymer composite to form a "green" LDH/natural fiber/biopolymer hybrid composite. The resultant hybrid material (viz LDH/natural fiber/biopolymer hybrid composite) may exhibit enhanced mechanical properties, thermal stability, and flammability resistance and can be used in applications such as environmental protection and flame retardancy.

Author Contributions: M.J.M. and S.I.M. co-designed and guided the review as well as co-writing Sections 1-3, 6 and 7 of the article; J.S.S. and E.R.S. co-wrote Sections 4, 5 and 8; T.C.M. and M.J.M. co-wrote Sections 9 and 10; while M.J.M. and S.I.M. compiled the article together. All authors have read and agreed to the published version of the manuscript.

Funding: This research was funded by the National Research Foundation (NRF) of South Africa, grant number (s) 127278 and 114270 .

Acknowledgments: The National Research Foundation (NRF) of South Africa is acknowledged for financial support.

Conflicts of Interest: The authors declare no conflict of interest.

\section{References}

1. Mittal, V. Polymer layered silicate nanocomposites: A review. Materials 2009, 2, 992-1057. [CrossRef]

2. Huang, G.; Zhuo, A.; Wang, L.; Wang, X. Preparation and flammability properties of intumescent flame retardant-functionalized layered double hydroxides/polymethyl methacrylate nanocomposites. Mater. Chem. Phys. 2011, 130, 714-720. [CrossRef]

3. Pereira, C.M.C.; Herrero, M.; Labajos, F.M.; Marques, A.T.; Rives, V. Preparation and properties of new flame retardant unsaturated polyester nanocomposites based on layered double hydroxides. Polym. Degrad. Stab. 2009, 94, 939-946. [CrossRef]

4. Du, L.; Qu, B.; Zhang, M. Thermal properties and combustion characterization of nylon 6/MgAl-LDH nanocomposites via organic modification and melt intercalation. Polym. Degrad. Stab. 2007, 92, 497-502. [CrossRef]

5. Benaddi, H.; Benachour, D.; GrOHens, Y. Preparation and characterization of polystyrene-MgAl layered double hydroxide nanocomposite using bulk polymerization. J. Polym. Eng. 2015, 36, 681-693. [CrossRef]

6. Dinari, M.; Rajabi, A.R. Structural, thermal and mechanical properties of polymer nanocomposites based on organosoluble polyimide with naphthyl pendent group and layered double hydroxide. High Perform. Polym. 2016, 29, 951-959. [CrossRef]

7. Elbasuney, S. Surface engineering of layered double hydroxide (LDH) nanoparticles for polymer flame retardancy. Powder Technol. 2015, 277, 63-73. [CrossRef]

8. Kaul, P.K.; Samson, A.J.; Selvan, G.T.; Enoch, I.V.M.V.; Selvakumar, P.M. Synergistic effect of LDH in the presence of organophosphate on thermal and flammable properties of an epoxy nanocomposite. Appl. Clay Sci. 2017, 135, 234-243. [CrossRef]

9. Manzi-Nshuti, C.; Songtipya, P.; Manias, E.; Jimenez-Gasco, M.M.; Hossenlopp, J.M.; Wilkie, C.A. Polymer nanocomposites using aluminium and magnesium aluminium oleate layered double hydroxides: Effects of LDH divalent metals on dispersion, thermal, mechanical and fire performance in various polymers. Polymer 2009, 50, 3564-3574. [CrossRef]

10. Scarpellini, D.; Falconi, C.; Gaudio, P.; Mattoccia, A.; Medaglia, P.G.; Orsini, A.; Pizzoferrato, R.; Richetta, M. Morphology of $\mathrm{Zn} / \mathrm{Al}$ layered double hydroxidenanosheets grown onto aluminum thin films. Microelectron. Eng. 2014, 126, 129-133. [CrossRef]

11. Cavani, F.; Trifiro, F; Vaccari, A. Hydrotalcite-type anionic clays: Preparation, properties and applications. Catal. Today 1991, 11, 173-301. [CrossRef]

12. Bröcker, F.J.; Kainer, L. German Patent, 2024282, 1970; UK Patent 1342020, 1971.

13. Evans, D.G.; Slade, R.C.T. Structural aspects of layered double hydroxides. In Layered Double Hydroxides; Springer: Berlin/Heidelberg, Germany, 2006; pp. 1-87. 
14. Zamarreno, I.; Plana, F.; Vazquez, A.; Clague, D.A. Motukoreaite: A common alteration product in submarine basalts. Am. Mineral. 1989, 74, 1054-1058.

15. Drits, V.A.; Lisitsyna, N.A.; Cherkashin, V.I. New mineral varieties from the hydrotalcite-manas seite group as products of the low-temperature transformations of basalts and volcanogenic sedimentary-rocks of the ocean bottom. Dokl. Akad. Nauk SSSR 1985, 284, 443-447.

16. Halcom, Y.F.M. Layered Double Hydroxides: Morphology, Interlayer Anion and the Origins of Life. Ph.D. Thesis, University of North Texas, Denton, TX, USA, 2003.

17. Rives, V. Characterisation of layered double hydroxides and their decomposition products. Mater. Chem. Phys. 2002, 75, 19-25. [CrossRef]

18. Bouzaid, J.M.; Frost, R.L.; Martens, W.N. Thermal decomposition of the composite hydrotalcites of iowaite and woodallite. J. Therm. Anal. Calorim. 2007, 89, 511-519. [CrossRef]

19. Palmer, S.J.; Spratt, H.J.; Frost, R.L. Thermal decomposition of hydrotalcites with variable cationic ratios. J. Therm. Anal. Calorim. 2009, 95, 123-129. [CrossRef]

20. Tong, D.S.; Zhou, C.H.C.; Li, M.Y.; Yu, W.H.; Beltramini, J.; Lin, C.X.; Xu, Z.P.G. Structure and catalytic properties of Sn-containing layered double hydroxides synthesized in the presence of dodecylsulfate and dodecylamine. Appl. Clay Sci. 2010, 48, 569-574. [CrossRef]

21. Kloprogge, J.T.; Wharton, D.; Hickey, L.; Frost, R.L. Infrared and Raman study of interlayer anions $\mathrm{Co}_{3}{ }^{2-}$, $\mathrm{NO}^{3-}, \mathrm{SO}_{4}{ }^{2-}$ and $\mathrm{ClO}^{4-}$ in $\mathrm{Mg} / \mathrm{Al}$-hydrotalcite. Am. Mineral. 2002, 87, 623-629. [CrossRef]

22. Tao, Q.; Reddy, B.J.; He, H.; Frost, R.L.; Yuan, P.; Zhu, J. Synthesis and infrared spectroscopic characterization of selected layered double hydroxides containing divalent Ni and Co. Mater. Chem. Phys. 2008, 112, 869-875. [CrossRef]

23. Khan, A.I.; O'Hare, D. Intercalation chemistry of layered double hydroxides: Recent developments and applications. J. Mater. Chem. 2002, 12, 3191-3198. [CrossRef]

24. De Roy, A.; Forano, C.; El Malki, K.; Besse, J.-P. Anionic clays: Trends in pillaring chemistry. In Expanded Clays and Other Microporous Solids; Springer: Boston, MA, USA, 1992; pp. 108-169.

25. Brindley, G.W.; Kikkawa, S. Thermal behavior of hydrotalcite and of anion-exchanged forms of hydrotalcite. Clay Clay Miner. 1980, 28, 87-91. [CrossRef]

26. Komarneni, S.; Kozai, N.; Roy, R. Novel function for anionic clays: Selective transition metal cation uptake by diadochy. J. Mater. Chem. 1998, 8, 1329-1331. [CrossRef]

27. Bujoli-Doeuff, M.; Force, L.; Gadet, V.; Verdaguer, M.; El Malki, K.; De Roy, A.; Besse, J.P.; Renard, J.P. A new two-dimensional approach to molecular-based magnets: Nickel (II)-chromium (III) double hydroxide systems. Mater. Res. Bull. 1991, 26, 577-587. [CrossRef]

28. Adachi-Pagano, M.; Forano, C.; Besse, J.-P. Delamination of layered double hydroxides by use of surfactants. Chem. Commun. 2000, 91-92. [CrossRef]

29. Choy, J.H.; Kewk, S.Y.; Jeong, Y.J.; Park, J.S. Inorganic layered double hydroxides as nonviral vectors. Angew. Chem. Int. Ed. 2000, 39, 4041. [CrossRef]

30. Ambrogi, V.; Fardella, G.; Grandolini, G.; Perioli, L. Intercalation compounds of hydrotalcite-like anionic clays with antiinflammatory agents-I. Intercalation and in vitro release of ibuprofen. Int. J. Pharm. 2001, 220, 23-32. [CrossRef]

31. Tyner, K.M.; Roberson, M.S.; Berghorn, K.A.; Li, L.; Gilmour, R.F., Jr.; Batt, C.A.; Giannelis, E.P. Intercalation, delivery, and expression of the gene encoding green fluorescence protein utilizing nanobiOHybrids. J. Control. Release 2004, 100, 399-409. [CrossRef]

32. Sharma, S.K.; Kushwaha, P.K.; Srivastava, V.K.; Bhatt, S.D.; Jasra, R.V. Effect of hydrothermal conditions on structural and textural properties of synthetic hydrotalcites of varying $\mathrm{Mg} / \mathrm{Al}$ ratio. Ind. Eng. Chem. Res. 2007, 46, 4856-4865. [CrossRef]

33. Renaudin, G.; Francois, M.; Evrard, O. Order and disorder in the lamellar hydrated tetracalcium monocarboaluminate compound. Cem. Concr. Res. 1999, 29, 63-69. [CrossRef]

34. Costantino, U.; Marmottini, F.; Nocchetti, M.; Vivani, R. New Synthetic Routes to Hydrotalcite-Like Compounds-Characterisation and Properties of the obtained Materials. Eur. J. Inorg. Chem. 1998, 1998, 1439-1446. [CrossRef]

35. Ogawa, M.; Kaiho, H. Homogeneous precipitation of uniform hydrotalcite particles. Langmuir 2002, 18, 4240-4242. [CrossRef] 
36. Livage, J.; Henry, M.; Sanchez, C. Sol-gel chemistry of transition metal oxides. Prog. Solid State Chem. 1988, 18, 259-341. [CrossRef]

37. Prinetto, F.; Ghiotti, G.; Graffin, P.; Tichit, D. Synthesis and characterization of sol-gel Mg/Al and Ni/Al layered double hydroxides and comparison with co-precipitated samples. Micropor. Mesopor. Mater. 2000, 39, 229-247. [CrossRef]

38. Aramendía, M.A.; Borau, V.; Jiménez, C.; Marinas, J.M.; Ruiz, J.R.; Urbano, F.J. Comparative study of $\mathrm{Mg} / \mathrm{M}$ $(\mathrm{III})(\mathrm{M}=\mathrm{Al}, \mathrm{Ga}$, In) layered double hydroxides obtained by coprecipitation and the sol-gel method. J. Solid State Chem. 2002, 168, 156-161. [CrossRef]

39. Jitianu, M.; Bãlãsoiu, M.; Zaharescu, M.; Jitianu, A.; Ivanov, A. Comparative study of sol-gel and coprecipitated Ni-Al hydrotalcites. J. Sol-Gel Sci. Technol. 2000, 19, 453-457. [CrossRef]

40. Lopez, T.; Bosch, P.; Ramos, E.; Gomez, R.; Novaro, O.; Acosta, D.; Figueras, F. Synthesis and Characterization of Sol-Gel Hydrotalcites. Structure and Texture. Langmuir 1996, 12, 189-192. [CrossRef]

41. Duan, X.; Evans, D.G. Layered Double Hydroxides; Springer Science \& Business Media: Berlin/Heidelberg, Germany, 2006; Volume 119.

42. Carlino, S.; Hudson, M.J. A thermal decomposition study on the intercalation of tris-(oxalato) ferrate (III) trihydrate into a layered $(\mathrm{Mg} / \mathrm{Al})$ double hydroxide. Solid State Ion. 1998, 110, 153-161. [CrossRef]

43. Ukrainczyk, L.; Chibwe, M.; Pinnavaia, T.J.; Boyd, S.A. ESR study of cobalt (II) tetrakis (N-methyl-4-pyridiniumyl) porphyrin and cobalt (II) tetrasulfophthalocyanine intercalated in layered aluminosilicates and a layered double hydroxide. J. Phys. Chem. 1994, 98, 2668-2676. [CrossRef]

44. Kooli, F.; Depege, C.; Ennaqadi, A.; De Roy, A.; Besse, J.P. Rehydration of Zn-Al layered double hydroxides. Clay Clay Miner. 1997, 45, 92-98. [CrossRef]

45. Tagaya, H.; Sato, S.; Morioka, H.; Kadokawa, J.; Karasu, M.; Chiba, K. Preferential intercalation of isomers of naphthalenecarboxylate ions into the interlayer of layered double hydroxides. Chem. Mater. 1993, 5, 1431-1433. [CrossRef]

46. Chibwe, M.; Pinnavaia, T.J. Stabilization of a cobalt (II) phthalocyanine oxidation catalyst by intercalation in a layered double hydroxide host. J. Chem. Soc. Chem. Commun. 1993, 278-280. [CrossRef]

47. Conterosito, E.; Palin, L.; Antonioli, D.; Riccardi, M.P.; Boccaleri, E.; Aceto, M.; Milanesio, M.; Gianotti, V. On the Rehydration of organic Layered Double Hydroxides to form Low-ordered Carbon/LDH Nanocomposites. Inorganics 2018, 6, 79. [CrossRef]

48. Zhu, K.; Gao, Y.; Tan, X.; Chen, C. Polyaniline-modified Mg/Al layered double hydroxide composites and their application in efficient removal of Cr (VI). ACS Sustain. Chem. 2016, 4, 4361-4369. [CrossRef]

49. Youssef, A.M.; Moustafa, H.A.; Barhoum, A.; Abdel Hakim, A.E.-F.A.; Dufresne, A. Evaluation of the morphological, electrical and antibacterial properties of polyaniline nanocomposite based on Zn/Al-layered double hydroxides. ChemistrySelect 2017, 2, 8553-8566. [CrossRef]

50. Zheng, Y.; Chen, Y. Preparation of polypropylene/Mg- Allayered double hydroxides nanocomposites through wet pan-milling: Formation of a second-staging structure in LDHs intercalates. RSC Adv. 2017, 7, 1520-1530. [CrossRef]

51. Gerds, N.; Katiyar, V.; Koch, C.B.; Hansen, H.C.B.; Plackett, D.; Larsen, E.H.; Risbo, J. Degradation of L-polylactide during melt processing with layered double hydroxides. Polym. Degrad. Stabil. 2012, 97, 2002-2009. [CrossRef]

52. Karami, Z.; Ganjali, M.R.; Dehaghani, M.Z.; Aghazadeh, M.; Jouyandeh, M.; Esmaeili, A.; Habibzadeh, S.; MOHaddespour, A.; Inamuddin, F.K.; Haponiuk, J.Z.; et al. Kinetics of cross-linking reaction of epoxy resin with hydroxyapatite-functionalized layered double hydroxides. Polymers 2020, 12, 1157. [CrossRef]

53. Zhao, W.; Du, Y.C.; Sun, Y.B.; Wang, J.C. Study on preparation of layered double hydroxides (LDHs) and properties of EPDM/LDHs composites. Plast. Rubber Compos. 2014, 43, 192-201. [CrossRef]

54. Chen, W.; Qu, B. LLDPE/ZnAl LDH-exfoliated nanocomposites: Effects of nanolayers on thermal and mechanical properties. J. Mater. Chem. 2004, 14, 1705-1710. [CrossRef]

55. Magagula, B.; Nhlapho, N.; Focke, W.W. $\mathrm{Mn}_{2} \mathrm{Al}-\mathrm{LDH}-$ and $\mathrm{Co}_{2} \mathrm{Al}-\mathrm{LDH}$-stearate as photodegradants for LDPE film. Polym. Degrad. Stabil. 2009, 94, 947-954. [CrossRef]

56. Ciou, C.-Y.; Li, S.-Y.; Wu, T.-M. Morphology and degradation behavior of poly(3-hydroxybutyrate-co-3 -hydroxyvalerate)/layered double hydroxides composites. Eur. Polym. J. 2014, 59, 136-143. [CrossRef] 
57. Huang, S.-C.; Deng, C.; Wang, S.-X.; Wei, W.-C.; Chen, H.; Wang, Y.-Z. Electrostatic action induced interfacial accumulation of layered double hydroxides towards highly efficient flame retardance and mechanical enhancement of thermoplastic polyurethane/ammonium polyphosphate. Polym. Degrad. Stabil. 2019, 165, 126-136. [CrossRef]

58. Costantino, U.; Bugatti, V.; Gorrasi, G.; Montanari, F.; Nocchetti, M.; Tammaro, L.; Vittoria, V. New Polymeric Composites Based on Poly ( $\epsilon$-caprolactone) and Layered Double Hydroxides Containing Antimicrobial Species. ACS Appl. Mater. Interfaces 2009, 1, 668-677. [CrossRef]

59. Bugatti, V.; Viscusi, G.; Di Bartolomeo, A.; Iemmo, L.; Zampino, D.C.; Vittoria, V.; Gorrasi, G. Ionic liquid as dispersing agent of LDH-carbon nanotubes into a biodegradable vinyl alcOHol polymer. Polymers 2020, 12, 495. [CrossRef]

60. Marek, A.A.; Verney, V.; Totaro, G.; Sisti, L.; Celli, A.; Cionci, N.B.; Gioia, D.D.; Massacrier, L.; Leroux, F. Organo-modified LDH fillers endowing multi-functionality to bio-based poly (butylene succinate): An extended study from the laboratory to possible market. Appl. Clay Sci. 2020, 188, 105502. [CrossRef]

61. Youssef, A.M.; Bujdosó, T.; Hornok, V.; Papp, S.; Dékány, I. Structural and thermal properties of polystyrene nanocomposites containing hydrophilic and hydrophobic layered double hydroxides. Appl. Clay Sci. 2013, 77, 46-51. [CrossRef]

62. Leng, J.; Kang, N.; De-Yi, W.; Falkenhagen, J.; Thünemann, A.F.; Schönhals, A. Structure-property relationship of nanocomposites based on polylactide and layered double hydroxides-comparison of $\mathrm{MgAl}$ and $\mathrm{NiAl} \mathrm{LDH}$ as nanofiller. Macromol. Chem. Phys. 2017, 218, 1700232. [CrossRef]

63. Quispe-Dominguez, R.; Naseem, S.; Leuteritz, A.; Kuehnert, I. Synthesis and characterization of MgAl-DBS LDH/PLA composite by sonication-assisted masterbatch (SAM) melt mixing method. RSC Adv. 2019, 9, 658-667. [CrossRef]

64. Nagendra, B.; MOHan, K.; Gowd, E.B. Polypropylene/layered double hydroxide (LDH) nanocomposites: Influence of LDH particle size on the crystallization behaviour of polypropylene. ACS Appl. Mater. Interfaces 2015, 7, 12399-12410. [CrossRef]

65. Guo, S.; Zhang, C.; Peng, H.; Wang, W.; Liu, T. Structural characterization, thermal and mechanical properties of polyurethane/CoAl layered double hydroxide nanocomposites prepared via in situ polymerization. Compos. Sci. Technol. 2011, 71, 791-796. [CrossRef]

66. Singh, M.; Somvanshi, D.; Singh, R.K.; Mahanta, A.K.; Maiti, P.; Misra, N.; Paik, P. Functionalized polyvinyl chloride/layered double hydroxide nanocomposites and its thermal and mechanical properties. J. Appl. Polym. Sci. 2020, 137, 48894. [CrossRef]

67. Barik, S.; Behera, L.; Badamali, S.K. Assessment of thermal and antimicrobial properties of PAN/Zn-Al layered double hydroxide nanocomposites. Compos. Interfaces 2017, 24, 579-591. [CrossRef]

68. Barik, S.; Badamali, S.K.; Behera, L.; Jena, P.K. Mg-Al LDH reinforced PMMA nanocomposites: A potential material for packaging industry. Compos. Interfaces 2018, 25, 369-380. [CrossRef]

69. Xie, J.; Zhang, K.; Zhao, Q.; Wang, Q.; Xu, J. Large-scale fabrication of linear low-density polyethylene/layered double hydroxides composite films with enhanced heat retention, thermal, mechanical, optical and water vapor barrier properties. J. Solid State Chem. 2016, 243, 62-69. [CrossRef]

70. Dong, S.; Jia, Y.; Xu, X.; Luo, J.; Han, J.; Sun, X. Crystallization and properties of poly(ethylene terephthalate)/layered double hydroxide nanocomposites. J. Colloid Interface Sci. 2018, 539, 54-64. [CrossRef] [PubMed]

71. Kumar, M.; Chaudhary, V.; Suresh, K.; Pugazhenthi, G. Synthesis and characterization of exfoliated PMMA/Co-Al LDH nanocomposites via solvent blending technique. RSC Adv. 2015, 5, 39810-39820. [CrossRef]

72. Qiu, L.; Chen, W.; Qu, B. Morphology and thermal stabilization mechanism of LLDPE/MMT and LLDPE/LDH nanocomposites. Polymer 2006, 47, 922-930. [CrossRef]

73. Suresh, K.; Kumar, M.; Pugazhenthi, G.; Uppaluri, R. Enhanced mechanical and thermal properties of polystyrene nanocomposites prepared using organo-functionalized NiAl layered double hydroxide via melt intercalation technique. J. Sci. Adv. Mater. Dev. 2017, 2, 245-254.

74. Guo, B.Z.; Zhao, Y.; Huang, Q.T.; Jiao, Q.Z. A new method to prepare exfoliated UV-cured polymer/LDH nanocomposites via nanoplatelet-like LDHs modified with N-Lauroyl-glutamate. Compos. Sci. Technol. 2013, 81, 37-41. [CrossRef] 
75. Hajibeygi, M.; Shabanian, M.; Khonakdar, H.A. Zn-Al LDH reinforced nanocomposites based on polyamide containing imide group: From synthesis to properties. Appl. Clay Sci. 2015, 114, 256-264. [CrossRef]

76. Hajibeygi, M.; Shafiei-Navid, S.; Shabanian, M.; Vahabi, H. Novel poly(amide-azomethine) nanocomposites reinforced with polyacrylic acid-co-2-acrylamido-2-methylpropanesulfonic acid modified LDH: Synthesis and properties. Appl. Clay Sci. 2018, 157, 165-176. [CrossRef]

77. Huang, G.; Chen, S.; Song, P.; Lu, P.; Wu, C.; Liang, H. Combination effects of graphene and layered double hydroxides on intumescent flame-retardant poly (methyl methacrylate) nanocomposites. Appl. Clay Sci. 2014, 88, 78-85. [CrossRef]

78. Wang, Q.; Zhang, X.; Wang, C.J.; Zhu, J.; Guo, Z.; O'Hare, D. Polypropylene/layered double hydroxide nanocomposites. J. Mater. Chem. 2012, 22, 19113-19121. [CrossRef]

79. Kredatusová, J.; Beneš, H.; Livi, S.; Pop-Georgievski, O.; Ecorchard, P.; Abbrent, S.; Pavlova, E.; Bogdał, D. Influence of ionic liquid-modified LDH on microwave-assisted polymerization of $\varepsilon$-Caprolactone. Polymer 2016, 100, 86-94. [CrossRef]

80. Jaerger, S.; Zawadzki, S.F.; Leuteritz, A.; Wypych, F. New alternative to produce colored polymer nanocomposites: Organophilic $\mathrm{Ni} / \mathrm{Al}$ and $\mathrm{Co} / \mathrm{Al}$ layered double hydroxide as fillers into low-density polyethylene. J. Braz. Chem. Soc. 2017, 28, 2391-2401. [CrossRef]

81. Zhang, S.; Liu, X.; Gu, X.; Jiang, P.; Sun, J. Flammability and thermal behavior of polypropylene composites containing dihydrogen phosphate anion-intercalated layered double hydroxides. Polym. Compos. 2015, 36, 2230-2237. [CrossRef]

82. Qian, Y.; Jiang, K.; Li, L. Improving the flame retardancy of ethylene vinyl acetate composites by incorporating layered double hydroxides based on bayer red mud. e-Polymers 2019, 19, 129-140. [CrossRef]

83. Zoromba, M.S.; Nour, M.A.; Eltamimy, H.E.; Abd El-Maksoud, S.A. Effect of modified layered double hydroxide on the flammability and mechanical properties of polypropylene. Sci. Eng. Compos. Mater. 2018, 25, 101-108. [CrossRef]

84. Lee, J.-H.; Zhang, W.; Ryu, H.-J.; Choi, G.; Choi, J.Y.; Choy, J.-H. Enhanced thermal stability and mechanical property of EVA nanocomposites upon addition of organo-intercalated LDH nanoparticles. Polymer 2019, 177, 274-281. [CrossRef]

85. Zhang, Z.; Qin, J.; Zhang, W.; Pan, Y.-T.; Wang, D.-Y.; Yang, R. Synthesis of a novel dual layered double hydroxide hybrid nanomaterial and its application in epoxy nanocomposites. Chem. Eng. J. 2020, 381, 122777. [CrossRef]

86. Qian, Y.; Qiao, P.; Li, L.; Han, H.; Zhang, H.; Chang, G. Hydrothermal synthesis of lanthanum-doped MgAl-layered double hydroxide/graphene oxide hybrid and its application as flame retardant for thermoplastic polyurethane. Adv. Polym. 2020, 2020, 1018093. [CrossRef]

87. Li, L.; Qian, Y.; Qiao, P.; Han, H.; Zhang, H. Preparation of LDHs based on bittern and its flame-retardant properties in EVA/LDHs properties. Adv. Polym. 2019, 2019, 4682164.

88. Qiu, L.; Gao, Y.; Zhang, C.; Yan, Q.; O’Hare, D.; Wang, Q. Synthesis of highly efficient flame-retardant polypropylene with surfactant intercalated layered double hydroxides. Dalton Trans. 2017, 47, 2965-2975. [CrossRef]

89. Nagendra, B.; Rosely, C.V.S.; Leuteritz, A.; Reuter, U. Polypropylene/layered double hydroxide nanocomposites: Influence of LDH intralayer metal constituents on the properties of polypropylene. ACS Omega 2017, 2, 20-31. [CrossRef]

90. Gao, Y.; Zhang, Y.; Williams, G.R.; O'Hare, D.; Wang, Q. Layered double hydroxide-oxidized carbon nanotube hybrids as highly efficient flame retardant nanofillers for polypropylene. Sci. Rep. 2016, 6, 35502. [CrossRef]

91. Gao, Y.; Wang, Q.; Lin, W. Ammonium polyphosphate intercalated layered double hydroxide and zinc borate as highly efficient flame Retardant nanofillers for polypropylene. Polymers 2018, 10, 1114. [CrossRef]

92. Li, L.; Jiang, K.; Qian, Y.; Han, H.; Qiao, P.; Zhang, H. Effect of organically intercalation modified layered double hydroxides-graphene oxide hybrids on flame retardancy of thermoplastic polyurethane nanocomposites. J. Therm. Anal. Calorim. 2020,1-11. [CrossRef]

93. Wang, B.-N.; Chen, N.-Y.; Yang, B.-J. Modification and compounding of CaMgAl-Layered Double Hydroxides and their application in the flame retardance of acrylonitrile-butadiene-styrene resin. Polymers 2019, 11, 1623. [CrossRef]

94. Dou, Y.; Zhou, A.; Pan, T.; Han, J.; Wei, M.; Evans, D.G.; Duan, X. Humidity-triggered self-healing films with excellent oxygen barrier performance. Chem. Commun. 2014, 50, 7136-7138. [CrossRef] 
95. Pan, T.; Xu, S.; Dou, Y.; Liu, X.; Li, Z.; Han, J.; Yan, H.; Wei, M. Remarkable oxygen barrier films based on a layered double hydroxide/chitosan hierarchical structure. J. Mater. Chem. A 2015, 3, 12350-12356. [CrossRef]

96. Han, J.; Dou, Y.; Wei, M.; Evans, D.G.; Duan, X. Erasable nanoporous antireflection coatings based on the reconstruction effect of layered double hydroxides. Angew. Chem. Int. Ed. 2010, 49, 2171-2174. [CrossRef] [PubMed]

97. Gu, Y.; Lu, Z.; Chang, Z.; Liu, J.; Lei, X.; Li, Y.; Sun, X. NiTi layered double hydroxide thin films for advanced pseudocapacitor electrodes. J. Mater. Chem. A. 2013, 1, 10655-10661. [CrossRef]

98. Xu, Z.P.; Braterman, P.S. High affinity of dodecylbenzene sulfonate for layered double hydroxide and resulting morphological changes. J. Mater. Chem. 2003, 13, 268-273. [CrossRef]

99. Merchán, M.; Ouk, T.S.; Kubát, P.; Lang, K.; Coelho, C.; Verney, V.; Commereuc, S.; Leroux, F.; Sol, V.; Taviot-Guého, C. Photostability and photobactericidal properties of porphyrin-layered double hydroxide-polyurethane composite films. J. Mater. Chem. B 2013, 1, 2139-2146. [CrossRef] [PubMed]

100. Yoo, J.T.; Lee, S.B.; Lee, C.K.; Hwang, S.W.; Kim, C.R.; Fujigaya, T.; Nakashima, N.; Shim, J.K. Graphene oxide and laponite composite films with high oxygen-barrier properties. Nanoscale 2014, 6, 10824-10830. [CrossRef]

101. Huang, H.-D.; Liu, C.-Y.; Li, D.; Chen, Y.-H.; Zhong, G.-J.; Li, Z.-M. Ultra-low gas permeability and efficient reinforcement of cellulose nanocomposite films by well-aligned graphene oxide nanosheets. J. Mater. Chem. A 2014, 2, 15853-15863. [CrossRef]

102. Wu, C.-N.; Yang, Q.; Takeuchi, M.; Saito, T.; Isogai, A. Highly tough and transparent layered composites of nanocellulose and synthetic silicate. Nanoscale 2014, 6, 392-399. [CrossRef]

103. Möller, M.W.; Lunkenbein, T.; Kalo, H.; Schieder, M.; Kunz, D.A.; Breu, J. Barrier Properties of Synthetic Clay with a Kilo-Aspect Ratio. Adv. Mater. 2010, 22, 5245-5249. [CrossRef]

104. Dou, Y.; Xu, S.; Liu, X.; Han, J.; Yan, H.; Wei, M.; Evans, D.G.; Duan, X. Transparent, flexible films based on layered double hydroxide/cellulose acetate with excellent oxygen barrier property. Adv. Funct. Mater. 2014, 24, 514-521. [CrossRef]

105. Huang, Y.-W.; Cheng, S. Carboxylate-intercalated layered double hydroxides for H2 sorption. J. Mater. Chem. A 2014, 2, 13452-13463. [CrossRef]

106. Wang, M.; Li, H.; Du, C.; Liang, Y.; Liu, M. Preparation and Barrier Properties of Nanocellulose/Layered Double Hydroxide Composite Film. BioResources 2018, 13, 1055-1064. [CrossRef]

107. Wang, L.; Dou, Y.; Wang, J.; Han, J.; Liu, L.; Wei, M. Layer-by-layer assembly of layered double hydroxide/rubber multilayer films with excellent gas barrier property. Compos. Part A Appl. Sci. Manuf. 2017, 102, 314-321. [CrossRef]

108. Yang, W.; Xia, Y.; Liu, X.; Yang, J.; Liu, Y. Layered double hydroxides/reduced graphene oxide nanocomposites with enhanced barrier properties. Polym. Compos. 2018, 39, 3841-3848. [CrossRef]

109. Botan, R.; Pinheiro, I.F.; Ferreira, F.V.; Lona, L.M.F. Correlation between water absorption and mechanical properties of polyamide 6 filled layered double hydroxides (LDH). Mater. Res. Express 2018, 5, 65004. [CrossRef]

110. Kotal, M.; Srivastava, S.K.; Bhowmick, A.K.; Chakraborty, S.K. Morphology and properties of stearate-intercalated layered double hydroxide nanoplatelet-reinforced thermoplastic polyurethane. Polym. Int. 2011, 60, 772-780. [CrossRef]

111. Feng, J.; Liao, Z.; Zhu, J.; Su, S. Comparison of morphology and mechanical properties of peroxide-cured acrylonitrile butadiene rubber/LDH composites prepared from different organically modified LDHs. J. Appl. Polym. Sci. 2013, 127, 3310-3317. [CrossRef]

112. Suresh, K.; Pugazhenthi, G.; Uppaluri, R. Properties of polystyrene (PS)/Co-Al LDH nanocomposites prepared by melt intercalation. Mater. Today 2019, 9, 333-350. [CrossRef]

113. Dong, Y.; Zhu, Y.; Dai, X.; Zhao, D.; Zhou, X.; Qi, Y.; Koo, J.H. Ammonium alcOHol polyvinyl phosphate intercalated LDHs/epoxy nanocomposites. J. Therm. Anal. Calorim. 2015, 122, 135-144. [CrossRef]

114. Mao, L.; Liu, J.-Y.; Zheng, S.-J.; Wu, H.-Q.; Liu, Y.-J.; Li, Z.-H.; Bai, Y.-K. Mussel-inspired nano-silver loaded layered double hydroxides embedded into a biodegradable polymer matrix for enhanced mechanical and gas barrier properties. RSC Adv. 2019, 9, 5834-5843. [CrossRef]

115. Moyo, L.; Focke, W.W.; Heidenreich, D.; Labuschagne, F.J.W.J.; Radusch, H.J. Properties of layered double hydroxide micro-and nanocomposites. Mater. Res. Bull. 2013, 48, 1218-1227. [CrossRef] 
116. Qin, Y.; Wang, L.; Wang, X. A high performance sensor based on PANI/ZnTi-LDHs nanocomposite for trace NH3 detection. Org. Electron. 2019, 66, 102-109. [CrossRef]

117. Otoukesh, M.; Es'haghi, Z.; Feizy, J.; Nerin, C. Graphene oxide/Layered Double Hydroxides@ Sulfonated Polyaniline: A sorbent for ultrasonic assisted dispersive solid phase extraction of phthalates in distilled herbal beverages. J. Chromatogr. A 2020, 1625, 461307. [CrossRef]

118. Shamitha, C.; Mahendran, A.; Anandhan, S. Effect of polarization switching on piezoelectric and dielectric performance of electrospun nanofabrics of poly (vinylidene fluoride)/Ca-Al LDH nanocomposite. J. Appl. Polym. Sci. 2020, 137, 48697. [CrossRef]

119. Wang, H.; Wu, J.; Zheng, L.; Cheng, X. Preparation and properties of ZnAl layered double hydroxide/Polycaprolactone nanocomposites for use in drug delivery. Polym. Plast. Technol. 2019, 58, 1027-1035. [CrossRef]

120. Chakraborti, M.; Jackson, J.K.; Plackett, D.; Gilchrist, S.E.; Burt, H.M. The application of layered double hydroxide clay (LDH)-poly (lactide-co-glycolic acid)(PLGA) film composites for the controlled release of antibiotics. J. Mater. Sci. Mater. Med. 2012, 23, 1705-1713. [CrossRef] [PubMed]

121. Kang, N.J.; Wang, D.Y.; Kutlu, B.; Zhao, P.C.; Leuteritz, A.; Wagenknecht, U.; Heinrich, G. A new approach to reducing the flammability of layered double hydroxide (LDH)-based polymer composites: Preparation and characterization of dye structure-intercalated LDH and its effect on the flammability of polypropylene-grafted maleic anhydride/d-LDH composites. ACS Appl. Mater. Interfaces 2013, 5, 8991-8997.

122. Troutier-Thuilliez, A.L.; Taviot-Guého, C.; Cellier, J.; Hintze-Bruening, H.; Leroux, F. Layered particle-based polymer composites for coatings: Part, I. Evaluation of layered double hydroxides. Prog. Org. Coat. 2009, 64, 182-192. [CrossRef]

123. Yang, B.; Cai, J.; Wei, S.; Nie, N.; Liu, J. Preparation of Chitosan/NiFe-Layered Double Hydroxides Composites and Its Fenton-Like Catalytic oxidation of Phenolic Compounds. J. Polym. Environ. 2020, 28, 343-353. [CrossRef]

124. Zhang, S.; Yan, Y.; Wang, W.; Gu, X.; Li, H.; Li, J.; Sun, J. Intercalation of phosphotungstic acid into layered double hydroxides by reconstruction method and its application in intumescent flame retardant poly (lactic acid) composites. Polym. Degrad. Stabil. 2018, 147, 142-150. [CrossRef]

125. Jia, X.; Gao, S.; Liu, T.; Li, D.; Tang, P.; Feng, Y. Fabrication and bifunctional electrocatalytic performance of ternary CoNiMn layered double hydroxides/polypyrrole/reduced graphene oxide composite for oxygen reduction and evolution reactions. Electrochim. Acta 2017, 245, 59-68. [CrossRef]

126. Alnaqbi, M.A.; Samson, J.A.; Greish, Y.E. Electrospun Polystyrene/LDH Fibrous Membranes for the Removal of Cd2+ Ions. J. Nanomater. 2020, 2020, 1-12. [CrossRef]

127. Singh, M.; Singh, R.K.; Singh, S.K.; Mahto, S.K.; Misra, N. In vitro biocompatibility analysis of functionalized poly (vinyl chloride)/layered double hydroxide nanocomposites. RSC Adv. 2018, 8, 40611-40620. [CrossRef] 